\title{
Incidental Findings in TMJ Imaging
}

\author{
Kaan Orhan, Seçil Aksoy, Ismail Hakan Avsever, \\ and Kaan Gündüz
}

\subsection{Incidental Findings in TMJ Imaging}

MRI has been usually used to obtain information from the soft tissue of the TMJ especially for evaluating the articular disc and its pathology. Even if small field of view (FOV) and surface coils are used in TMJ MR imaging, it should be expected that some incidental findings may appear outside the primary area of interest. These incidental findings are common in TMJ MRIs. Orhan et al. [1] evaluated the incidental findings in TMJ MRI and found 117 incidental findings in 15\% of the patients.

\subsubsection{Epidermoid Cyst}

Most commonly known as a sebaceous cyst but also known as epidermoid inclusion cyst or epidermal cyst is a slow-growing benign cyst which arises from the epidermis and develops out of the ectodermal tissue. Histologically the lining of

K. Orhan $(\varangle)$

Department of Dentomaxillofacial Radiology, Ankara University, Faculty of Dentistry, Ankara, Turkey

\section{S. Aksoy}

Department of Dentomaxillofacial Radiology, Near East University, Faculty of Dentistry, Mersin, Turkey

\section{H. Avsever}

Health Sciences University, Faculty of Gulhane Dentistry, Department of Dentomaxillofacial

Radiology, Ankara, Turkey

K. Gündüz

Ondokuz Mayıs University, Faculty of Dentistry, Department of Dentomaxillofacial

Radiology, Samsun, Turkey 
the cyst contains only epithelium [2]. Panoramic radiographs are not able to show these cysts even if they are located on the dentomaxillofacial region. Epidermoid cyst usually appears as a hypoattenuated well-circumscribed cystic mass with near cerebrospinal fluid (CSF) density on computed tomography (CT) images and does not enhance after the administration of the contrast material [3]. This nontender and dome-shaped cyst has low signal intensity on T1-W images while high signal intensity in T2-W images with focal low signal intensity debris [4]. Cyst signal intensity in MRI is varying broadly according to the composition of the cyst, but most of the intracranial epidermoid cysts have low signal intensity on T1-W images and high or equal signal on T2-W images when compared the cerebral cortex [5]. While DWI demonstrates high signal intensity, ADC maps have iso- or slightly hyperintense relative to the brain tissue [6]. Seven percent of epidermoid cyst is seen in head and neck region, whereas in oral cavity they account for only $1.6 \%[7]$.

\subsubsection{Arachnoid Cyst}

Arachnoid cysts are CFS-filled sacs that appear in the arachnoid membrane which is lining the brain (intracranial) and spinal cord (spinal). These cysts have low signal intensity on T1-W images, and high signal intensity on T2-W images resembles to the CSF [8]. Arachnoid cysts are usually asymptomatic and found incidentally on CT or MR images. It was determined as a CSF-like density mass in CT scans with a 0-20 Hounsfield unit (HU) attenuation values. They can cause the remodeling of the bony wall in calvaria, may compress the adjacent brain tissue, and do not enhance after the contrast material $[9,10]$. It is important to differentiate the arachnoid and epidermoid cysts; both have the same signal intensity in conventional MR sequences; DWI is used in this situation, showing characteristic high signal for ECs compared with low signal for arachnoid cysts with very high diffusivity [6, 10] (Figs. 11.1 and 11.2).
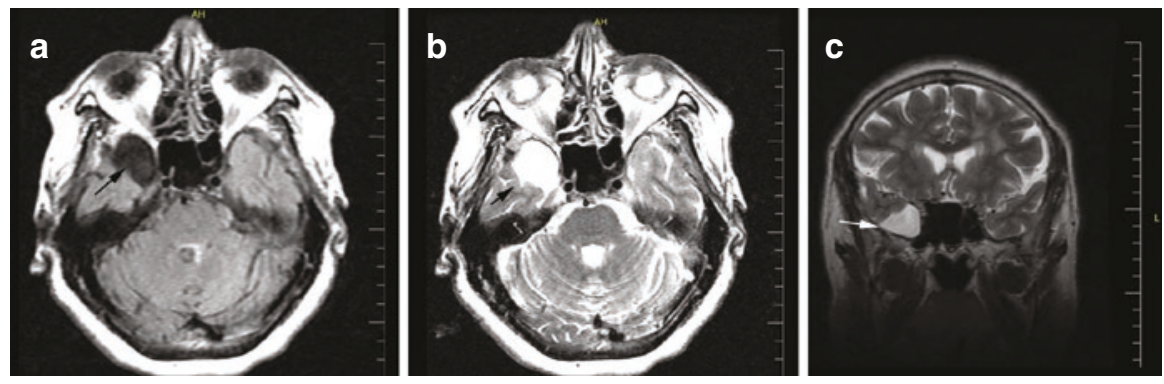

Fig. 11.1 A lesion of CSF intensity appearance displaces the temporal lobe posteriorly (arrow). T1 and T2-W images shows no enhancement. Features are characteristic of an arachnoid cyst (arrows) 

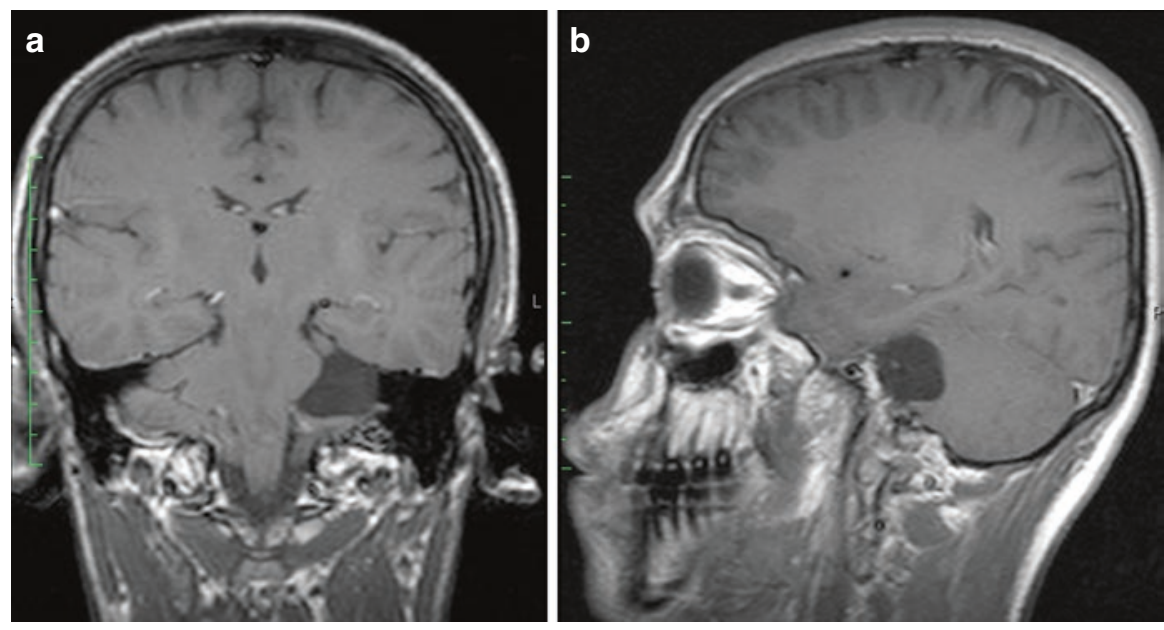

Fig. 11.2 A typical arachnoid cyst. (a) Low signal intensity on T1-W images, (b) high signal intensity on $\mathrm{T} 2-\mathrm{W}$ images

\subsubsection{Thornwald Cyst}

Thornwald cyst (also spelled as a Thornwaldt cyst or Tornwaldt cyst) is a common incidental benign lesions located in the superficial surface of the superior constrictor muscle and lined by the respiratory epithelium [11]. Obstruction of the pharyngeal bursa that communicates the roof of the nasopharynx and notochord causes the development of the Thornwald cyst [12] and does not involve the adjacent bony structures. This cyst appears as a hyperintense area on both T1- and T2-W images due to the high proteinaceous content concentration $[12,13]$. If the cyst contains less protein, it will appear as hypo- or isointense on T1-W and hyperintense on $\mathrm{T} 2-\mathrm{W}$ images. After the gadolinium injection, the cyst content will not enhance [12]. Most of the patients are asymptomatic and found incidentally on images or while performing nasal endoscopic examination. CT images show low-attenuation soft tissue mass in the high posterior midline nasopharynx, and image characteristics are similar to CSF [12, 13] (Fig. 11.3).

\subsubsection{Nasopharyngeal/Squamous Cell Carcinoma}

Nasopharyngeal carcinoma (NPC) is a primary malignancy of the nasopharynx originating from the epithelial cells in lateral wall of the nasopharynx especially around the fossa of Rosenmuller and the Eustachian cushion [14-16]. Nasopharyngeal carcinoma is classified as squamous cell carcinoma and nonkeratinizing carcinoma (subdivided this type to differentiated nonkeratinizing carcinoma and undifferentiated carcinoma 
Fig. 11.3 A typical Thornwald cyst appearing on MR images as hyperintense area due to the high proteinaceous content

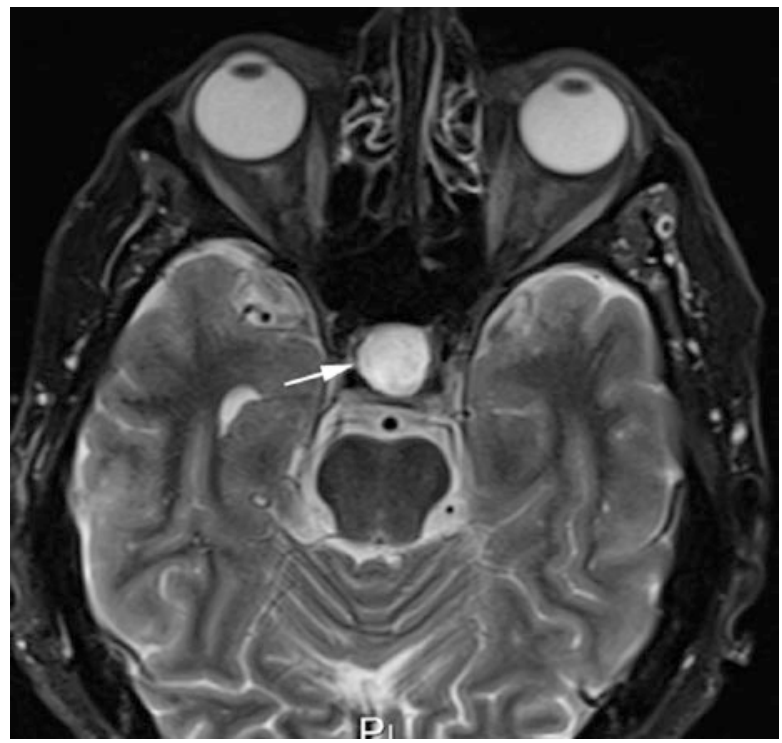

subtypes) by the World Health Organization (WHO) [17]. Etiological factors of this malignancy include the Epstein-Barr virus (EBV) (especially in children), genetic susceptibility and environmental carcinogens, and consumption of food (in particular salted fish) containing carcinogenic volatile nitrosamines [14]. MRI is sensitive than CT to perineural spread and for demonstrating early the bone marrow changes of infiltration (see normal bone marrow signal of the clivus), although not all bone marrow changes represent tumor extension. Signal characteristics on T1-W typically isointense to muscle, on T2-W image isointense to somewhat hyperintense to muscle fat saturation is helpful. Postcontrast sequences should be fat-saturated; prominent heterogeneous enhancement is typical. Perineural extension should be taken into consideration [18]. On CT images it is difficult to differentiate the small nasopharyngeal carcinomas from the muscles in consequent of resemblance density of the tumor with muscles [10].

\subsubsection{Pleomorphic Adenoma}

Pleomorphic adenomas (also known as benign mixed tumor) are the most common salivary gland tumors (accounts for approximately $60-70 \%$ of all benign tumors of the salivary glands), which mostly affect the superficial lobe of the parotid gland [19]. Pleomorphic adenoma is originating from the ductal epithelium of both salivary glands containing epithelial and mesenchymal components. The CT appearance of pleomorphic adenoma is well-defined mass that has parallel density to the muscle and shows mild to moderate contrast enhancement [10, 19]. This tumor represents various signal intensities in different MRI sequences such as relatively hypointense on T1-W images, isointense on proton 
density-weighted images, and hyperintense on T2-W images [20]. Pleomorphic adenomas have hypoechoic appearance compared with the normal parenchyma of the salivary gland on ultrasound (US). Also this tumor most commonly has lobulated shape, well-defined borders, heterogeneous echotexture, distal acoustic enhancement, and grade 0 or 1 vascularity. Peripheral vascularity is common in more than half of this tumor [21]. Ultrasound elastography shows generally heterogeneous stiff appearance, but this feature is not specific for the pleomorphic adenoma and may be seen also in a significant portion of the malignant tumor [22]. Klintworth et al. [23] defined specific elastographic findings for parotid gland tumors, and they reported that "dens core" sign (with a central zone of very stiff tissue with softer tissue in the vicinity) is specifically related with pleomorphic adenoma (Fig. 11.4).

\subsubsection{Warthin's Tumor}

Warthin's tumor, also known as a papillary cystadenoma lymphomatosum, adenolymphoma, lymphomatous adenoma, is the second most common benign neoplasm of the salivary gland and is arising from the ductal component of them [20]. More males than females suffer from this tumor, and it is found bilaterally in $10 \%$ of patients [18]. Warthin's tumor has low signal intensity on T1-W images compared with the high signal intensity of the parotid gland. On T2-W images tumor is heterogeneous and variable in signal intensity [10]. On CT scans, tumor density is equivalent to soft tissue or cystic density [20]. This tumor has hypoechoic appearance on US like the pleomorphic adenoma comparing with the normal parenchyma. Characteristic sonographic features of the Warthin's tumor include generally oval shape, well-defined borders, distal acoustic enhancement, heterogeneous echotexture, and grade 2 or 3 vascularity with central or mixed perfusion. Also more than half of the tumors have cystic areas [21]. Klintworth et al. [23] reported that "halfhalf" sign (with a stiff area located in the superficial half of a lesion while the deeper part has a softer appearance) is specifically related with Warthin's tumor.

\subsubsection{Oncocytoma}

Oncocytoma is a rare benign tumor arising from large, eosinophilic, granular, polygonal epithelial cells. This tumor usually occurs in the eighth decade of life with a slightly female predominance [24]. This tumor has variable tissue signal on different MR sequences such as relatively hypointense on T1-W images, intermediate on fat-saturated T2-W, and postcontrast T1-W images [10]. CT scans demonstrate the homogeneous well-circumscribed tumoral mass showing moderate enhancement after the contrast material administration [25]. This tumor has no specific imaging features and represents well-defined, hypoechoic solid mass with posterior enhancement on US [26]. 

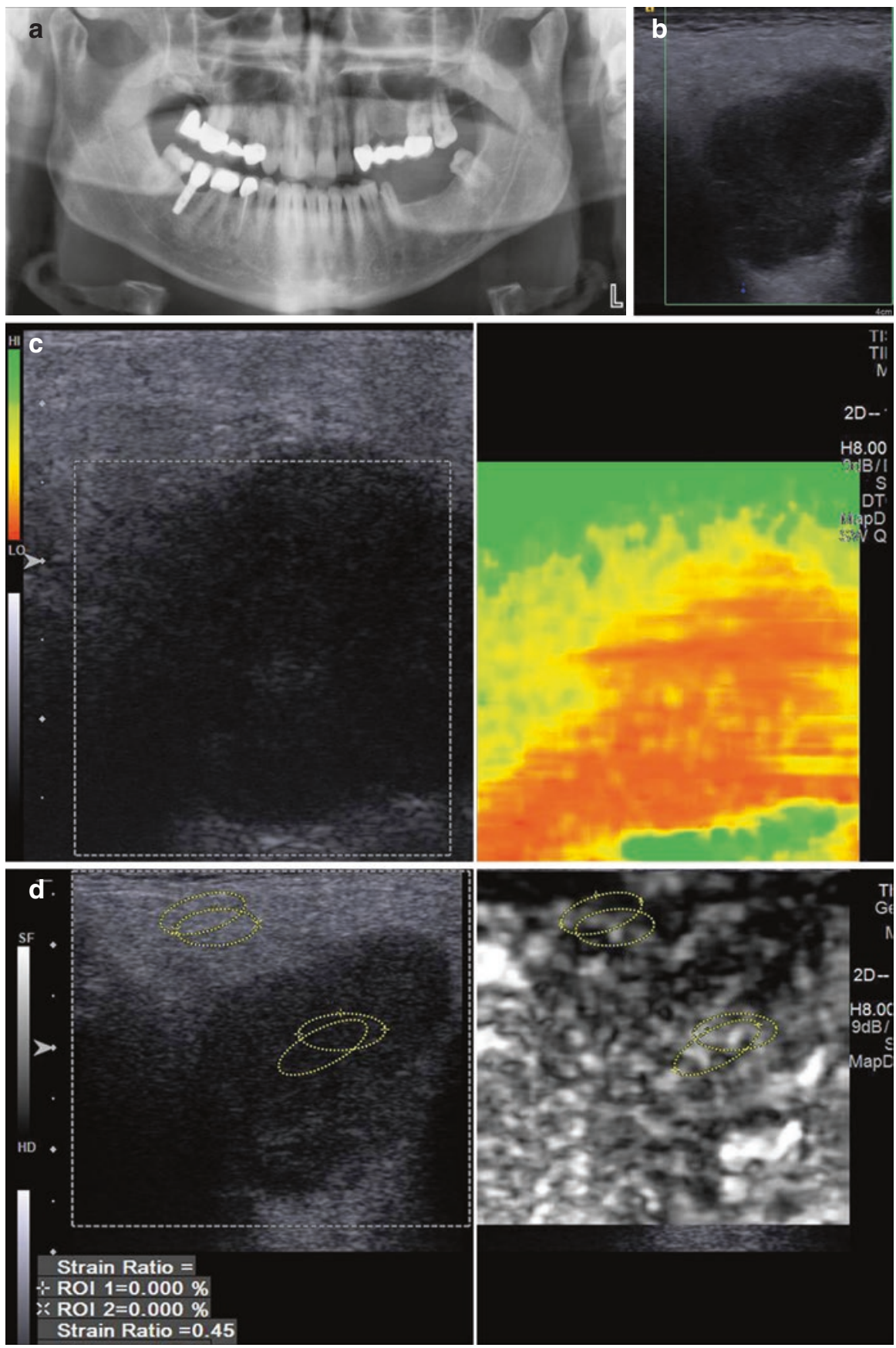

Fig. 11.4 (a) Panoramic radiography of a 45-year-old male patient who presented with pain, swelling, and limited mouth opening in right TMJ. The panoramic radiography showing flattening of both TMJs, (b) USG of the right parotid region revealed a huge mass in the parotid gland with hypoechoic nature, (c) sonoelastography of the lesion revealed an intermedia but predominantly soft lesion, (d) strain ration of the lesion, later diagnosed as pleomorphic adenoma of the parotid gland 

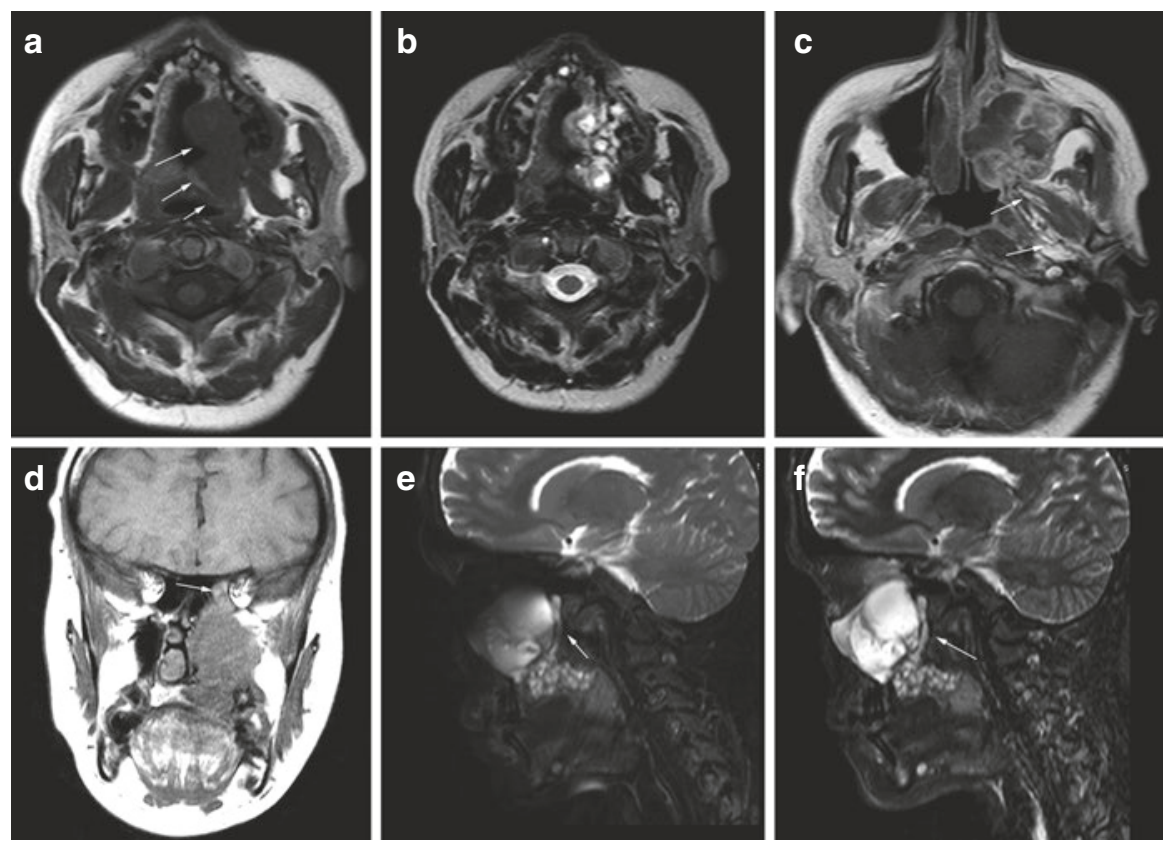

Fig. 11.5 A 28-year-old female patient with adenoid cystic carcinoma, (a) T1-W image isointense to hypointense compared to muscles (arrow), (b) T2-W image high signal intensity with different signal intensity areas, (c) T1 C+Mr. showing the spread of the tumor into the masticator space through TMJ area, (d) coronal T1-W image showing the extend and spread of the lesion into cranial fossa, (e) T2-W images showing perineural spread using fossa pterygopalatine (arrow), (f) STIR images also showing clearly perineural spread (arrow)

\subsubsection{Adenoid Cystic Carcinoma}

Adenoid cystic carcinoma (ACC) is a malignant tumor of secretory glands and most commonly located in major and minor salivary glands. ACC accounts for $23 \%$ of malignant salivary gland tumors, but most of the tumors occur in the minor salivary gland [20]. Most common localization of the ACC is hard palate [27]. Perineural invasion of ACC is more common and allows the tumors to spread the parapharyngeal space or intracranial tissues that can be determined with MRI or CT [19]. CT scans demonstrate the ACC isodense to muscle [10]. This tumor has no specific imaging features and represents hypoechoic cystic mass on US images. Postcontrast MRI demonstrates the nerve enhancement and enlargement in perineural invasion [20]. This tumor has intermediate signal intensity on T1-W images and slightly high signal intensity on T2-W images [28] (Fig. 11.5).

\subsubsection{Lymphomas of Major Salivary Glands}

Lymphomas generally occur with the neoplastic proliferation of the lymphoid cells in lymph nodes. However lymphomas arise not only from the lymph nodes but also 

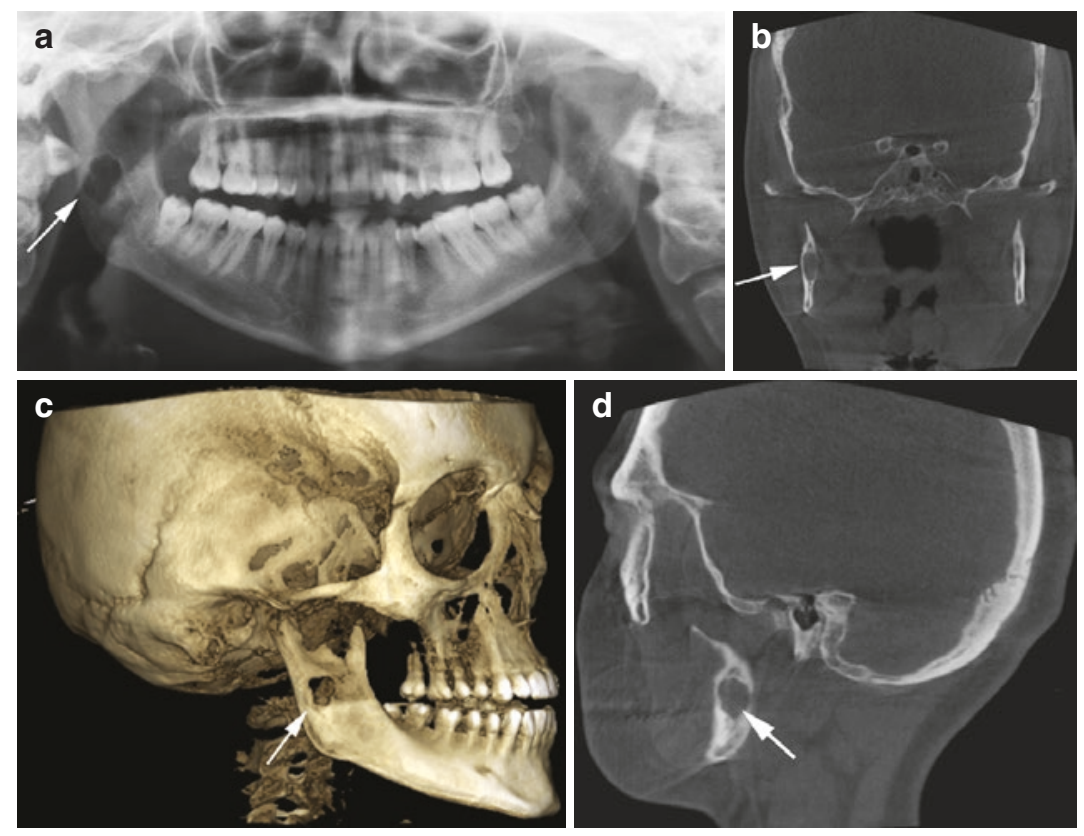

Fig. 11.6 (a) Panoramic radiography of 24-year-old female patient who presented with pain and limited mouth opening around TMJ, showing a solitary radiolucent lesion in the ramus of the mandible, (b) coronal CBCT image showing the thinning of the cortex of the mandible from the lingual region, (c, d) 3D and sagittal representation of the lesion. The lesion was diagnosed as histopathologically a rare plasmacytoma case

from the extranodal areas such as salivary gland, Waldeyer ring, gastrointestinal system, bone and tonsils, etc. [20]. Among them, the most common site of extranodal localization is parotid and submandibular gland [29]. Primary location of the neoplastic proliferation of the lymphoid cells in the salivary gland is rare with an incidence of $1.7-7.7 \%$ of all major salivary gland tumors. This tumor affects predominantly females [24]. This tumor is isodense compared with the muscle and has well-circumscribed margins on CT scans. But extranodal extensions have less welldefined borders and necrosis areas. On MRI lymphomas are hypointense on T1-W images and hypo- to hyperintense on T2-W images [30]. US features of the nonHodgkin's lymphoma include hypoechoic lymphomatous node with peripheral and hilar vascularity [31] (Figs. 11.6, 11.7, and 11.8).

\subsubsection{Astrocytoma}

Astrocytomas are malignant tumors of the brain and spinal cord that originate from immortalized astrocytes which are a particular kind of glial cells, star-shaped cells in the cerebrum and spinal cord. These tumors are classified into the four World Health Organization (WHO) categories: Grade I includes pilocytic astrocytoma and subependymal giant cell astrocytoma; Grade II includes pleomorphic 

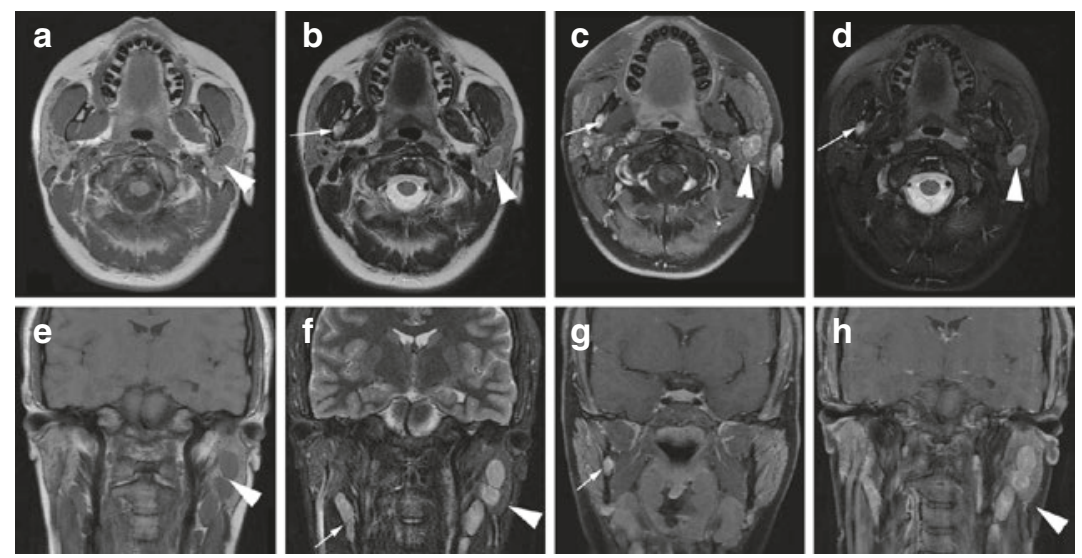

Fig. 11.7 (a-d) MR images of the same plasmacytoma case who incidentally diagnosed as nonHodgkin's lymphoma in the left parotid gland. Axial T1 image showing the lesion isointense to muscle. This lobulated lesion does involve the tail of the parotid gland. The mass shows high T2 signal, enhancement, and diffusion restriction (arrow head) and the right site arrow showing the plasmacytoma in the right ramus of the mandible. (e-h) The lesion is enhancing, multi-lobulated mass arising largely posteroinferior to the right parotid gland but involving the parotid tail consistent with multiple enlarged lymph nodes (arrow head); the corresponding site plasmacytoma in the mandible can also be seen on coronal T1-weighted images (arrow)
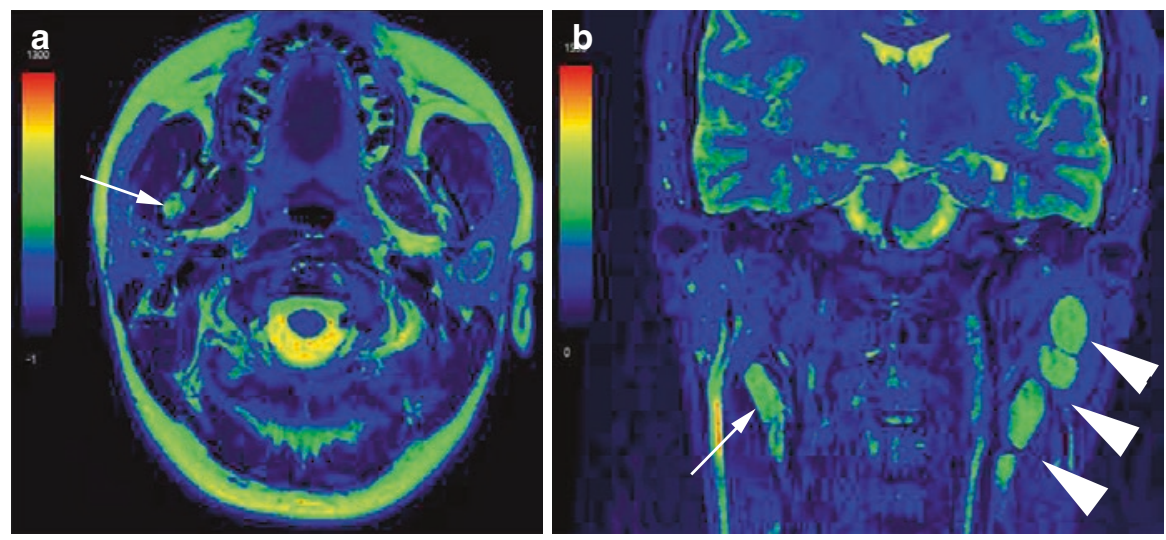

Fig. 11.8 (a, b) MR perfusion images; axial and coronal color ADC map shows the lesions as enhancing lesion with high ADC and a solid lesion (arrow) with intermediate ADC

xanthoastrocytoma, oligodendroglioma, and diffuse astrocytoma; Grade III includes anaplastic astrocytoma, anaplastic oligodendroglioma, and anaplastic pleomorphic xanthoastrocytoma; and Grade IV includes glioblastoma and diffuse midline glioma [32]. Spinal cord astrocytomas peak at third and fifth decades of life with a slightly male predominance. MRI is useful to demonstrate spinal cord edema, drop metastasis, and leptomeningeal spread [33]. Low-grade astrocytomas are determined as ill-defined areas of decreased attenuation involving the white matter on CT scans [34]. Low-grade astrocytomas are best seen on MRI with multimodality images. 

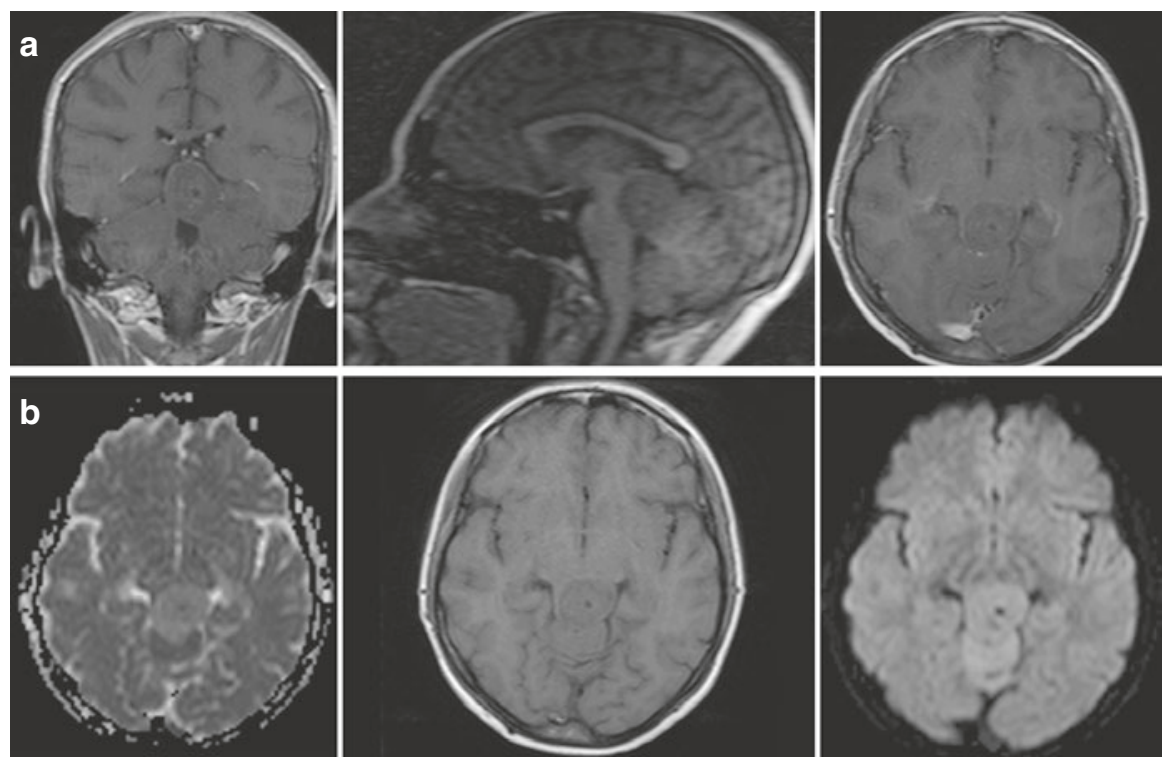

Fig. 11.9 An 18-year-old female patient with low-grade astrocytoma referred for temporal and TMJ pain. (a) T1-W image shows a lesion isointense to hypointense compared to white matter. (b) DWI has facilitated diffusion, with lower ADC values (arrows) with microcystic change which is a unique behavior for the infiltrative astrocytoma

T1-W image is isointense to hypointense compared to white matter and causes expansion of the adjacent cortex. T2/FLAIR is usually mass-like hyperintense signal. The "microcystic changes" along the lines of spread of the infiltrative astrocytoma are a unique behavior for the infiltrative astrocytoma. DWI/ADC typically has expedited diffusion, with lower ADC values suggesting a higher-grade tumor. Contrast is usually no enhancement, but small ill-defined areas of enhancement are not rare; however, when enhancement is seen, it should be considered as a warning sign for progression to a higher grade (Fig. 11.9).

\subsubsection{Meningioma}

Meningiomas are usually slow-growing tumors that develop from the meninges that surround the brain and spinal cord. This tumor is classified into three WHO categories: Grade I includes meningioma, Grade II includes atypical meningioma, and Grade III includes anaplastic (malignant) meningioma [32]. From these types approximately $80 \%$ of the cases occur in Grade I (benign) [24]. Incidental detection of asymptomatic meningiomas is getting higher with the advanced imaging modalities. Some of the conditions may be related with the growing tumor such as gender, hyperintensity on $\mathrm{T} 2-\mathrm{W}$ images, tumor size at the initial diagnosis, and tumor with no calcification [35]. On unenhanced CT, the tumor appears as hyperdense or isodense mass compared with the adjacent brain tissue and shows homogeneous enhancement after contrast material administration [19]. Spinal meningioma shows 

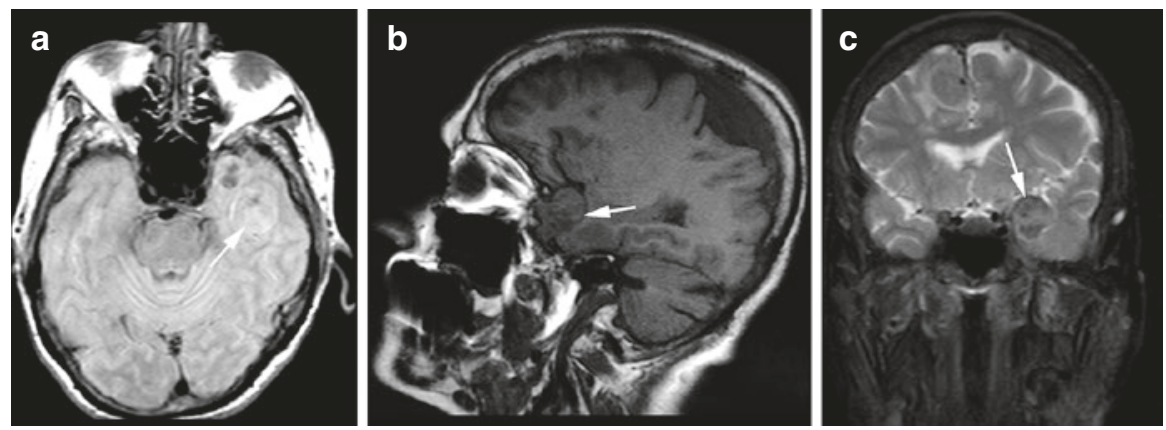

Fig. 11.10 (a) PD TSE TRA image showing isointense image in the left temporal region, (b) T1-W image showing same isointense image, (c) T2-W image showing heterogenous iso- to highintensity meningioma

isointensity relative to the spinal cord parenchyma on T1- and T2-W images [33]. Diffusion-weighted images may be useful for differentiating Grade I tumor from Grade II/III [36] (Fig. 11.10).

\subsubsection{Hemangiopericytoma}

Hemangiopericytoma is a kind of soft tissue sarcoma that arises from the Zimmerman's pericytes surrounding the blood vessels in various parts of the body [37] but predominantly located in the lower extremities, pelvis, or retroperitoneum [38]. Hemangiopericytomas have no gender predilection with a mean presentation in sixth and seventh decades of life [37]. Only $15 \%$ and $25 \%$ of the hemangiomapericytomas occur in the head and neck region [39]. On CT scans, hemangiopericytomas reveal round homogeneous masses with a sharp outline and often displace the adjacent structures [40, 41]. On T1-W images tumor shows intermediate signal intensity relative to the gray matter; after the gadolinium administration, it enhances heterogeneously [24]. Contrast T1-W images shows intense enhancement and heterogeneous signal intensity. There may be a dural tail sign in Grade II tumors. On T2-W images the lesion is isointense to gray matter multiple flow voids on MRI. DWI shows an intermediate restricted diffusion.

\subsubsection{Osteoma}

It is still unclear if osteomas are benign tumors or hamartomas. Osteomas originate from the cartilage and embryonal periosteum that are usually nodular or pedunculated polyp attached to the bone with a narrow stalk. It occurs almost exclusively in the head and neck region, particularly in the posterior mandible and also in paranasal sinuses especially in frontal sinuses and are most often encountered after 40 years of age [20]. Multiple osteomas which develop in the head and neck region and multiple epidermoid cysts of the skin and polyposis of the colon and rectum are 
the part of the Gardner syndrome [19, 20]. Histologically osteomas are divided into (1) ivory or compact osteoma, (2) spongious or trabecular osteoma, and (3) combination of the first two types [20, 42]. On MR T1-W and T2-W images, the ivory osteoma appears as a hypointense area and may be misinterpreted as air within the paranasal sinuses or nasal fossae [42]. While the CT appearance of the compact osteoma is very dense calcified, well-defined lesions, trabecular osteoma's density is changing depending on the fibrous component of the lesion [19, 42].

\subsubsection{Cholesteatoma}

Cholesteatoma is a destructive and expanding well-demarcated noncancerous cystic lesion consisting of keratinizing squamous epithelium in the middle ear and/or mastoid process [43, 44]. Cyst cavity is filled with the keratinous debris [45]. Cholesteatomas may be classified as either congenital or acquired types. Congenital cholesteatomas are derived from persistent embryologic remnants in the form of epithelial foci in the middle ear [44]. The pathogenesis of acquired cholesteatoma is explained on the invagination of the tympanic membrane, basal cell hyperplasia, epithelial in-growth through perforation, and squamous metaplasia of middle ear epithelium [43]. CT scans demonstrate the expansile nonenhancing hypodense lesions with neighboring smooth bony erosion [18]. Generally cholesteatomas have nonspecific signal intensity on basic MRI sequences, but non-echo planar diffusion-weighted imaging is more specific to diagnose these lesions and differentiate the primer and recurrent cholesteatoma. Cholesteatomas have high signal relative to the brain tissue on DWI [46, 47].

For cholesteatomatous tissue on MRI shows an intermediate to hypointense signal on T1-W images and appears hyperintense on the corresponding T2-W images. This hyperintensity is, however, significantly less as compared to that seen in inflammatory lesions [48]. Diffusion-weighted MRI is particularly sensitive to cholesteatoma tissue especially in diagnosis of intracranial and extracranial epidermoid cysts as middle ear cholesteatomas have similar histopathological characteristics to epidermoid cysts; this MR sequence should be used for evaluations such pathologies. Non-echo planar DWI for cholesteatoma diagnosis can be performed on $1.5 \mathrm{~T}$ or $3 \mathrm{~T}$ scanners indifferently. High sensitivity and negative predictive value and relatively lower specificity and positive predictive value are achieved by a single non-echo planar DWI protocol [49] (Fig. 11.11).

\subsubsection{Fibrosarcoma}

Fibrosarcoma is a malignant spindle cell tumor of fibrous connective tissue with herringbone architecture or interlacing fascicular pattern without expression of other connective tissue cell markers [50-53]. Fibrosarcomas have no sex predilection with a mean age in fourth decade [20]. Clinical diagnosis of the soft tissue sarcoma in the head and neck region is often a challenging problem due to growing in a considerable size without any symptoms, and even if the symptoms is present, 

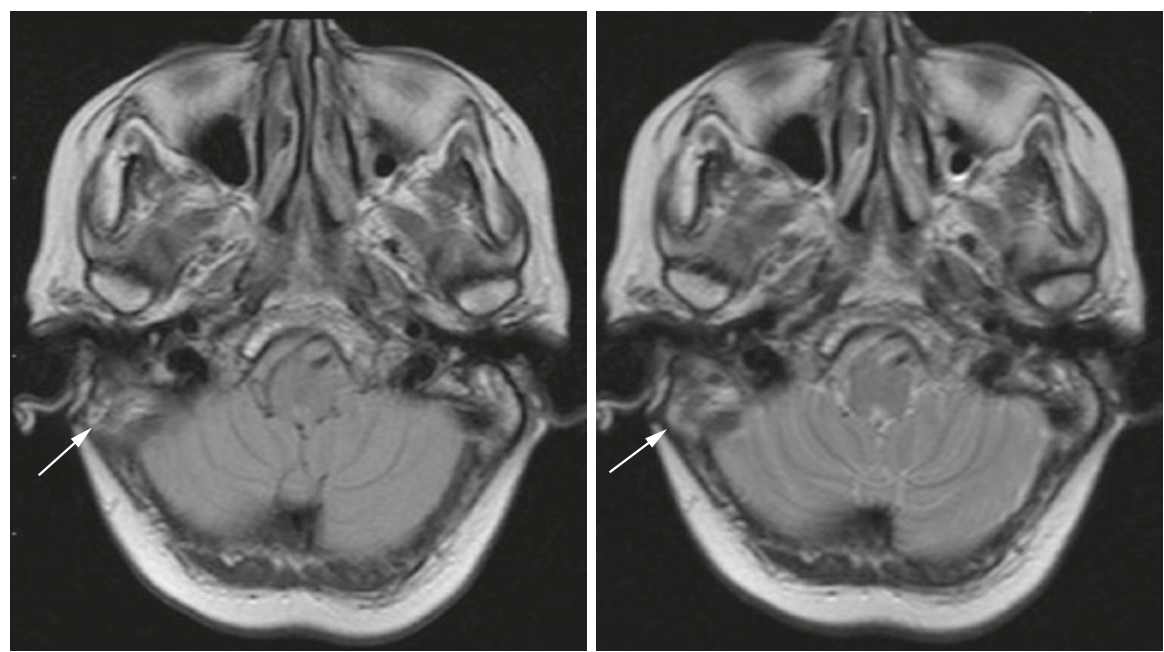

Fig. 11.11 Temporal bone, acquired cholesteatoma. T1-weighted axial MRI shows a soft tissue mass in the region of the right tegmen tympani (arrows)

it may be frequently overlooked as dental problem such as TMD [51, 52, 54]. On CT scans fibrosarcomas are determined as an isodense attenuating soft tissue masses. On T1-W images fibrosarcomas have low signal intensity and on T2-W images show both low and high signal intensity (heterogeneous) together in comparison with adjacent muscle [55].

\subsubsection{Otomastoiditis}

Otomastoiditis that can be classified into two distinct entities: acute and chronic otomastoiditis is an inflammatory disease of the middle air and mastoid air cells. While acute otomastoiditis may be related with the leukemia, mononucleosis, sarcoma of the temporal bone, and Kawasaki disease, chronic otomastoiditis is thought to be primarily due to Eustachian tube dysfunction [56-58]. Acute otomastoiditis presents opacification of the mastoid air cells [57, 58]. CT scans demonstrate the mastoid air cells filled with the soft tissue mass instead of the air [59]. MRI can be used for evaluating the otomastoiditis, however, with solely MRI it is difficult to diagnose the infection related to mastoid region. MRI characteristic of acute otomastoiditis are nonspecific debris within the middle ear and mastoid, possibly with several fluid levels which can be seen bright signal areas on T2-weighted images. For chronic otomastoiditis with cholesteatoma, MR signal characteristics are nonspecific; ordinarily, both $\mathrm{T} 1$ and $\mathrm{T} 2$ relaxation times are relatively long $[57,58]$. Signal characteristics are mostly low signal on T1-W and high signal on T2-W images. DWI/ADC diffusion restriction may be present; mucosal contrast enhancement is present in the majority of the cases on T1-W contrast images (Fig. 11.12). 

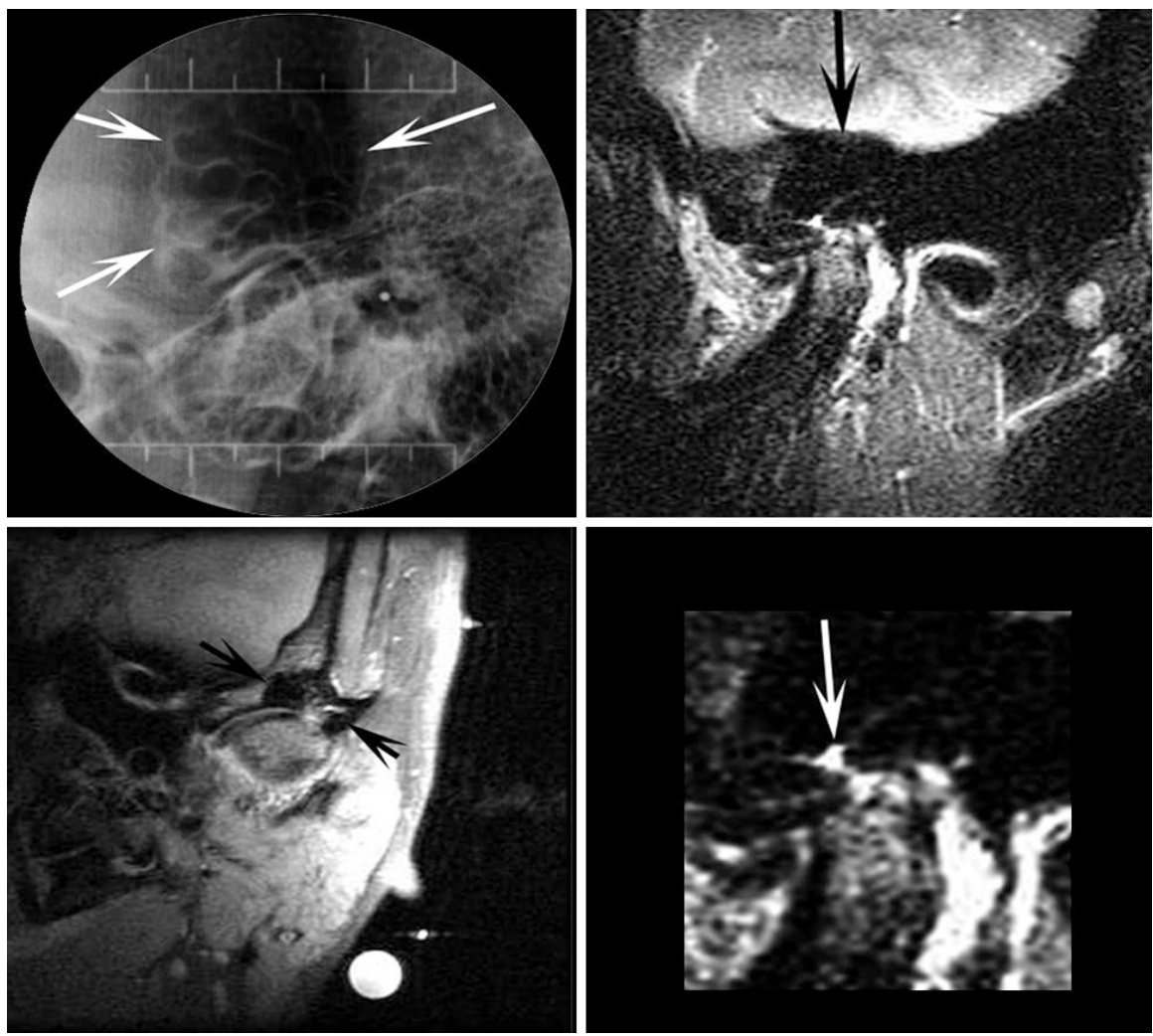

Fig. 11.12 MR images showing a well-pneumatized articular eminence and otomastoiditis at left articular eminence (arrows), coronal T1-W hypointense, while sagittal T2-W image showing bright signals above the TMJ condyle (arrows) (derived from [57])

\subsubsection{Empty Sella}

An empty sella is used to describe the extension of the subarachnoid space cerebrospinal fluid toward the intrasellar region through a defect in the diaphragma sella resulting in displacement of pituitary gland against the sellar wall with or without enlargement of the sella turcica [60]. Empty sella is divided into two types based on the reason: primary and secondary. Primary empty sella appears without any pathological changes in the pituitary gland, while secondary empty sella is caused by some pathologic conditions such as pituitary adenoma (radiation, drug or surgical therapy), postpartum pituitary necrosis, or lymphocytic hypophysitis [61]. Primary empty sella is asymptomatic and may be found incidentally, but secondary empty sella may be related to endocrine dysfunction, cerebrospinal fluid rhinorrhea, and visual abnormality. On CT scans an empty sella appears as a CSF or water-filled cavity density instead of normal pituitary gland tissue [62]. MRI is the modality of choice for confirming the diagnosis. On T1-W and T2-W images, empty sella shows the same signal intensity with cerebrospinal fluid [63]. Both MR images demonstrate 
Fig. 11.13 Coronal T1-W contrast-enhanced MR images showing a case of empty sella showing iso-/ high intense signal intensity with CSF leak in the middle part of the sella (arrows)

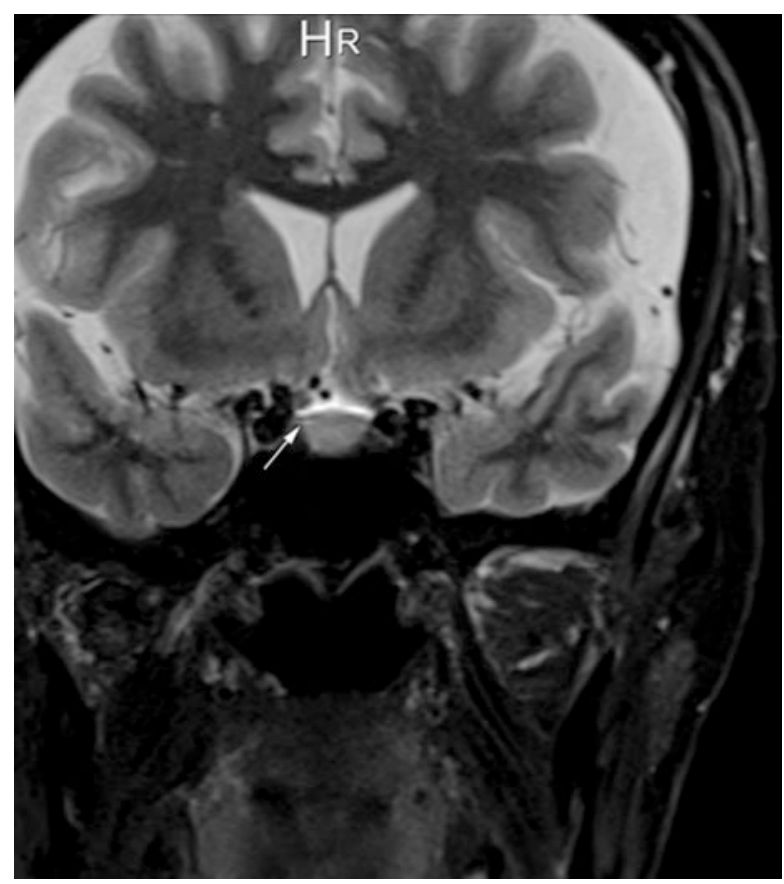

the sella to be filled with CSF, and the infundibulum can be seen to traverse the space, thereby excluding a cystic mass. This is known as the infundibulum sign (Fig. 11.13).

\subsubsection{Internal Carotid Artery (ICA) Dissection}

ICA dissection, like arterial dissection elsewhere, is a separation of the layers artery wall as a result of trauma and defects. As the blood enters the wall of the artery, thrombus form occurs which can lead to stroke, pseudoaneurysm, vessel occlusion, and stroke [64]. On CT, ICA dissections is eccentric lumen surrounded by the crescent shaped mural thickening which is hypodense relative to muscle $[65,66]$. Fatsaturated T1-W images are useful to identify this pathology [67]. MR images mostly shows a high signal crescent sign within the wall of the vessel which can be best seen T1 fat saturation or T2 and abnormal vessel contour on MR angiography (Fig. 11.14).

\subsubsection{Venous Angioma (VA)}

Venous angiomas (VA) are vascular malformations in which veins are the predominant vascular constituent. Because venous angiomas are infrequently symptomatic, their clinical significance remains unclear. When symptomatic, they are associated mainly with seizures or bleeding or headache or scatter pain around the area. Although cerebral angiography is the definitive study of choice, it is no longer 

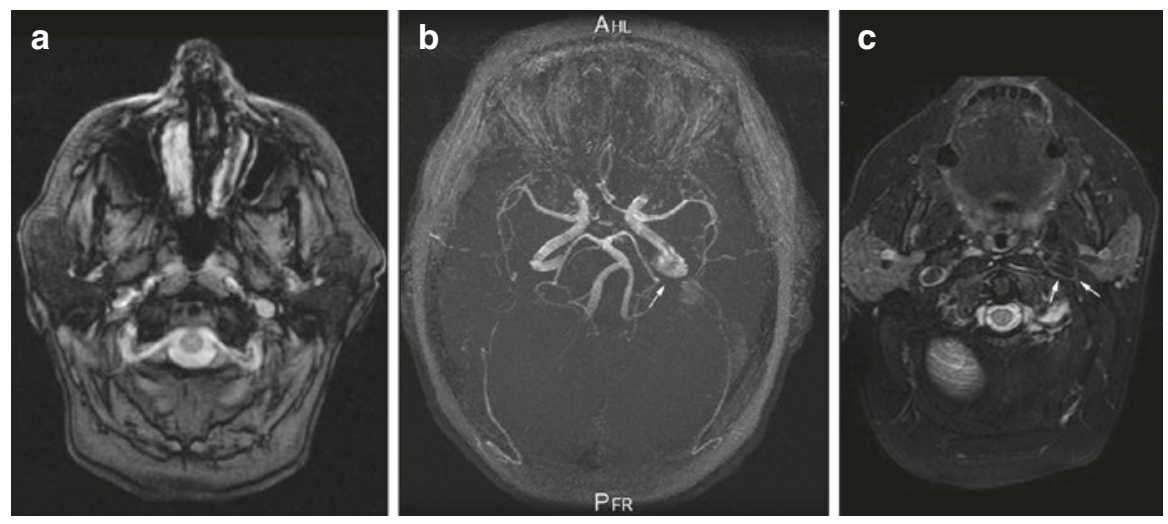

Fig. 11.14 (a) T1-W axial, (b) axial 3D TOF, (c) STIR images showing ICA on the left side (arrows)

judged necessary with uncomplicated vascular malformations. Cerebral developmental venous anomalies are usually incidentally detected and can be easily diagnosed as a linear or curvilinear focus of enhancement with contrast-enhanced CT images, and early CT findings of the VA include round, $1-2 \mathrm{~cm}$ focus enhancement [68]. Contrast-enhanced computed tomography (CT), which is no doubt responsible for the recent increase in the number of reported cases of VAS, is yielding to the far superior imaging ability of magnetic resonance (MR) as it becomes routinely available. MR imaging is thus becoming the primary study of choice. The most characteristic feature is an enlarged draining vein, followed by increased signal on T2-weighted images and decreased signal on T1-weighted images in adjacent parenchyma. T2 imaging is more successful in showing the lesions than T1 imaging. Best options are to find it as a gradient-echo or blood oxygen level-dependent sequence on MRI (Fig. 11.15).

\subsubsection{Schwannoma}

Temporal bone is also related to neuronal pathologies. One of them is a vestibular/ acoustic schwannoma that derives from glial-neurilemmal junction of nerve sheath, mostly vestibular division of the CN VIII. It is visible in the internal auditory meatus or cerebellopontine/pontine angle [69]. On CT scans schwannomas are usually oval or spindle in shape and have well-defined borders [70]. On contrast-enhanced CT, a schwannoma displays mottle central lucency with peripheral intensification. CT images demonstrate the tumor and neighboring bony structure relation and the erosion and destruction of the bone clearly [71]. Besides typical symptoms such as tinnitus and sensorineural hearing loss, patients also complain on headache, vertigo, facial pain, and weakness; even big lesions may often be incidental and asymptomatic findings. Large tumors may develop mass effect with cerebellar and brainstem symptoms, e.g., hydrocephalus and cranial nerve dysfunction other than CNVIII. The 

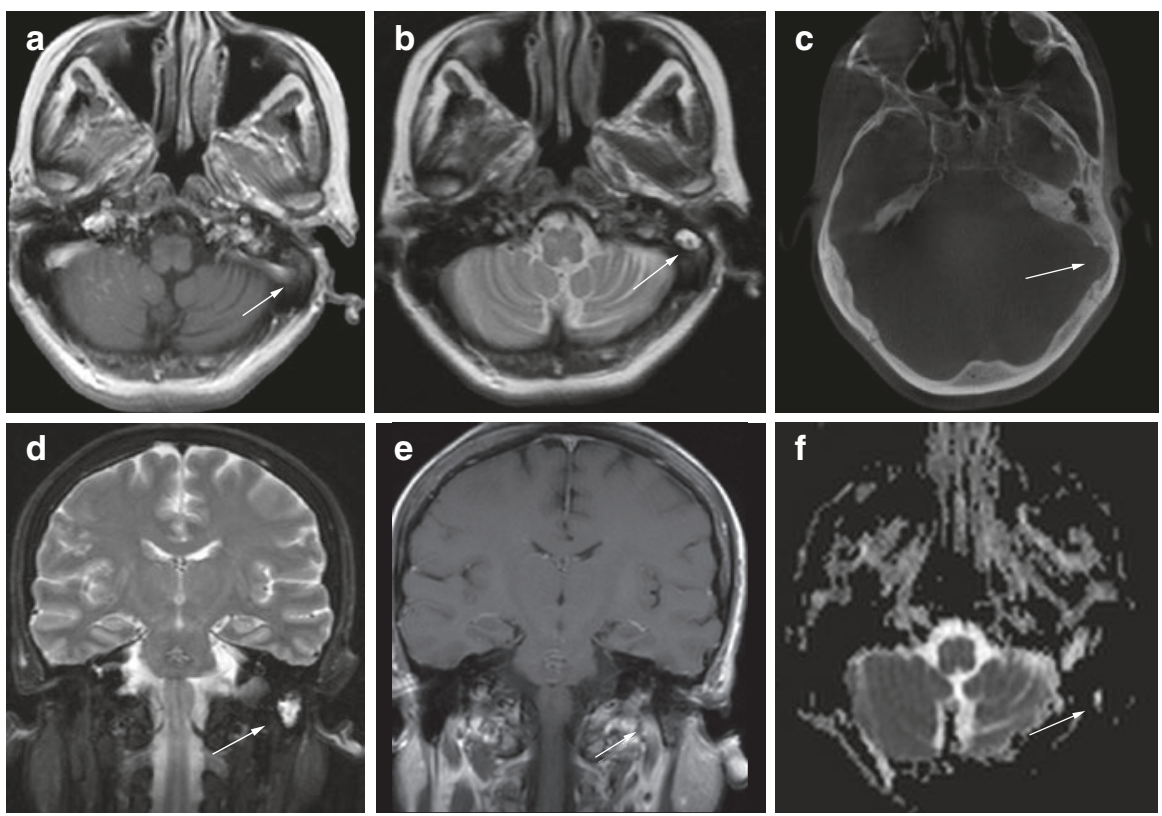

Fig. 11.15 A 62-year-old female patient referred with scattered pain around TMJ, (a) T1-W axial hypointense signal changes in the sigmoid sinus, (b) T2-W image shows the high signal intensity area, (c) axial CBCT showing an enlarged sigmoid sinus region, (d) coronal T2-W hyperintense, (e) coronal T1-W shows hypointense lesion, (f) DWI images diffusion restricted area which is consistent with venous angioma
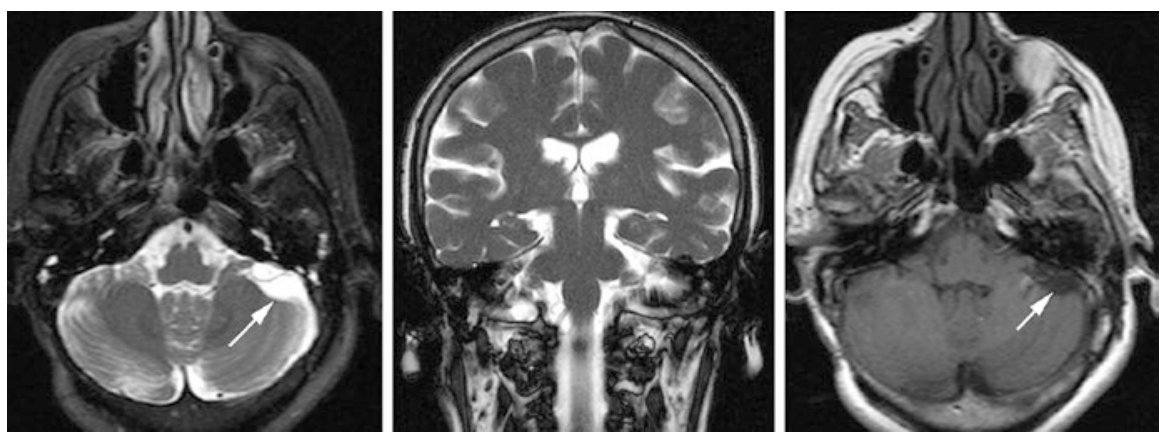

Fig. 11.16 A 38-year-old male patient with scattered pain around TMJ showing hypo- or isointense in T1- or heterogeneously hyperintense to adjacent brain in T2-weighted which is consistent with acoustic schwannoma

signal of the tumor is slightly hypo- or isointense in T1- or heterogeneously hyperintense to adjacent brain in T2-weighted images. Cystic areas show signal typical for fluid. In both modalities, most tumors show intense contrast enhancement with or without cystic degeneration and hemorrhagic areas (Fig. 11.16). 


\subsection{Incidental Calcifications in Maxillofacial Area}

\subsubsection{Tonsilloliths}

Tonsillar calcifications also known as "tonsilloliths" are white-yellowish-calcified deposits which are commonly located in tonsillar crypts. Mesolella et al. [72] reported that calcified masses occur with a variation of sizes ranging from a few millimeters to several centimeters. Small-sized calculi are common and asymptomatic, but the giantsized tonsilloliths are rare [73, 74]. Symptoms include dysphagia, recurrent sore throat, foreign body sensation, and halitosis [74]. The mechanisms of formation are still controversial. It is believed that they occurred due to repeated inflammation of the tonsillar crypts with recurrent tonsillitis. Repeated episodes of inflammation may cause cryptal fibrosis. Bacterial and epithelial debris accumulates within these crypts, and calcification occurs subsequent to the deposition of inorganic salts which derived from saliva [73, 75]. In addition, it is reported that tonsilloliths are primarily consisted of calcium hydroxyapatite/calcium carbonate and some other minerals such as magnesium, sodium, silica, potassium, copper, aluminum, iron, and ammonia radicals [72, $74,76]$. The most common cause of tonsillitis is viral infection including enteroviruses, particularly coxsackie virus, respiratory viruses (e.g., adenovirus, rhinovirus, influenza virus, coronavirus, parainfluenza virus, and respiratory syncytial virus), and viruses of the Herpesviridae family like Epstein-Barr virus (EBV), cytomegalovirus (CMV), and herpes simplex virus (HSV), while the most common bacterial pathogen is Group A $\beta$-hemolytic streptococcus in pediatric population [77].

Panoramic radiograph images can incidentally identify tonsilloliths as well as $\mathrm{CBCT}$ images [74]. Centurion et al. [78] suggested that CBCT images are more suitable to differentiate tonsilloliths than panoramic images. They are mostly seen as single or multiple, bilateral or unilateral, round, oval, dot-shaped, or irregular radiopacities around tonsillar area in $\mathrm{CBCT}$ scans. The study, which was conducted by Oda et al. [79], was reported that the prevalence of tonsilloliths was $46.1 \%$ in 482 CBCT scans. On MR images, it appears as hypo- to isointense to surrounding muscles on T1-W and hyperintense to surrounding muscles on T2-W images (Fig. 11.17).
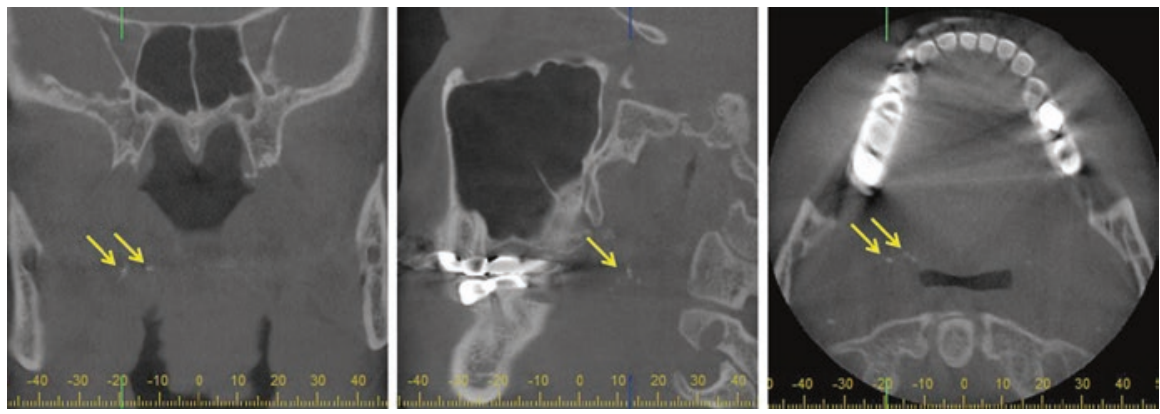

Fig. 11.17 Coronal, sagittal, and axial views of a CBCT image show multiple, irregular-shaped calcified masses in tonsillar region (arrows) 

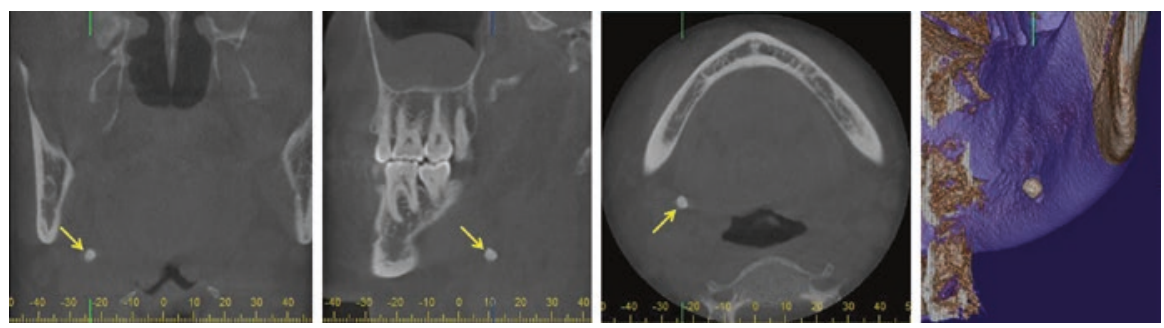

Fig. 11.18 Coronal, sagittal, axial, and 3D reconstructed views of a unilateral sialolith (arrows)

\subsubsection{Sialolith}

Salivary stones also known as "sialoliths" are described as an aggregation calcified deposits found within the salivary glands or ducts. It consists of hydroxyapatite, calcium and phosphate salts, desquamated epithelial cells, bacterial debris, and foreign bodies [20,80]. They frequently occur in submandibular gland or its ducts (80-90\%); calcified masses in the parotid and sublingual are, respectively, seen in $10-20 \%$ and $1-7 \%[20,80]$. They can also occur in minor salivary glands, primarily in the upper lip and buccal mucosa. According to literature, incidences of sialoliths are low, between $0.2 \%$ and $1.01 \%$ [81, 82].

The radiographic features are dependent on their internal structure. Homogeneously radiopaque deposits are easily seen in conventional radiographic techniques, but some of them have multiple layers of calcification. Low mineral content sialoliths are frequently seen in CBCT scans even they were asymptomatic [20]. No matter whether they are well calcified or not, salivary deposits are an incidental finding in TMJ CBCT images. If a sialolith is located in the ducts of salivary glands, then it is usually well defined, smooth, cylindric, round, or ovoid. On the contrary, if it tends to occur in the hilum of salivary gland, then it is larger and irregular-shaped [20, 83, 84] (Fig. 11.18).

\subsubsection{Antrolith/Rhinolith}

Antroliths are calcified masses which occurred in the paranasal sinuses [85]. If these calcified bodies occur in nasal cavity, then they are called as rhinolith [86]. These calcified bodies occur as a result of mineral salt deposition around a nidus within the nasal cavity. This core may be endogenous or exogenous. Endogenous sources could be originated from dental structures, blood, mucus, and bone fragments. Exogenous sources are the foreign bodies such as coin, bead, or weed introduced into the sinus cavities $[20,87]$. Antroliths occur within the maxillary sinus above the floor of the antrum; rhinoliths are found in nasal cavity [87]. Antroliths and rhinoliths can appear as incidental findings on CBCT. They are frequently asymptomatic unless they are larger $[88,89]$. According to literature, incidences of antroliths are between $0.12 \%$ and 3\% [90, 91] (Fig. 11.19). 

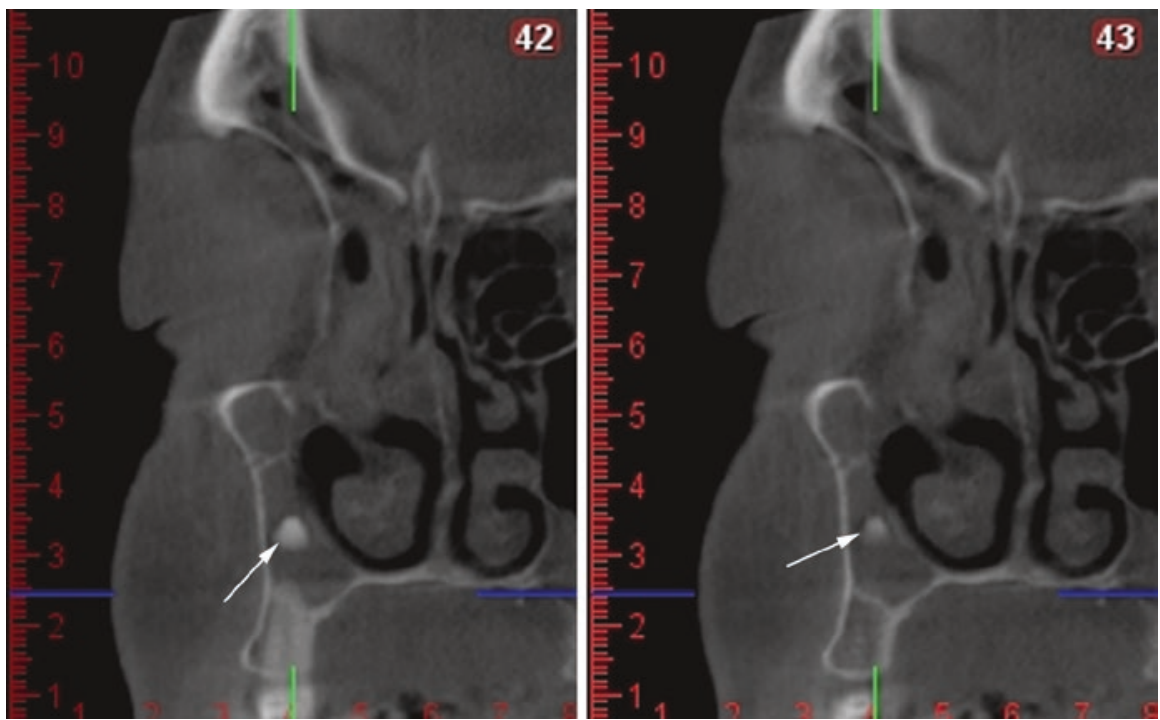

Fig. 11.19 Coronal views showing a calcified antrolith in the right maxillary sinus (arrows)

\subsubsection{Fungal Infection (Aspergilloma)}

Fungal infection of the sinuses is the inflammation of the lining mucosa of the paranasal sinuses due to fungal infection such as aspergillosis, mucormycosis, candidiasis, histoplasmosis, cryptococcosis, coccidioidomycosis, North American blastomycosis, rhinosporidiosis, and myospherulosis [58]. Fungal infection of the sinuses is classified as invasive and noninvasive due to the presence or absence of hyphae within the mucosal and other tissues of the paranasal sinuses [92] and divided into five subgroups. Aspergillosis is the most common fungal pathogen of the sinuses and usually affects the immunocompromised patients [93]. At noncontrast CT scans, aspergilloma is characterized by a hyperdense mass with occasional calcifications. This hyperattenuating lesion is usually surrounded by a hypodense mucosal thickening [94]. MR features can change due to the stage of the disease, mostly the lesions hypointensity on T1-WI and T2-WI. On T1-W image the lesion is hypointense because of the inflamed mucosal thickness and on T2-W usually appears as hyperintense peripheral inflamed mucosal thickness, and low T2 signal or signal void is due to high concentration of various metals such as iron, magnesium, and manganese concentrated by fungal organisms (Fig. 11.20).

\subsubsection{Osteoma Cutis}

Osteoma cutis is a rare soft tissue ossification in the skin or subcutaneous tissues. It is characterized a focal development of bone formation within the dermis. It may be primary but mostly secondary. Kishi et al. [95] reported a study which was based on 

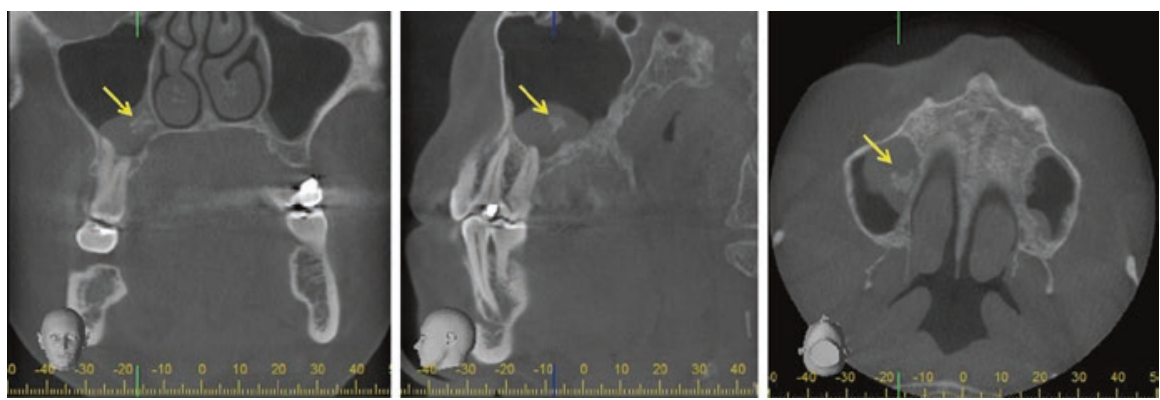

Fig. 11.20 An irregular calcified mass in the right maxillary sinus which was consisted with aspergillosis of the maxillary sinus (arrows)
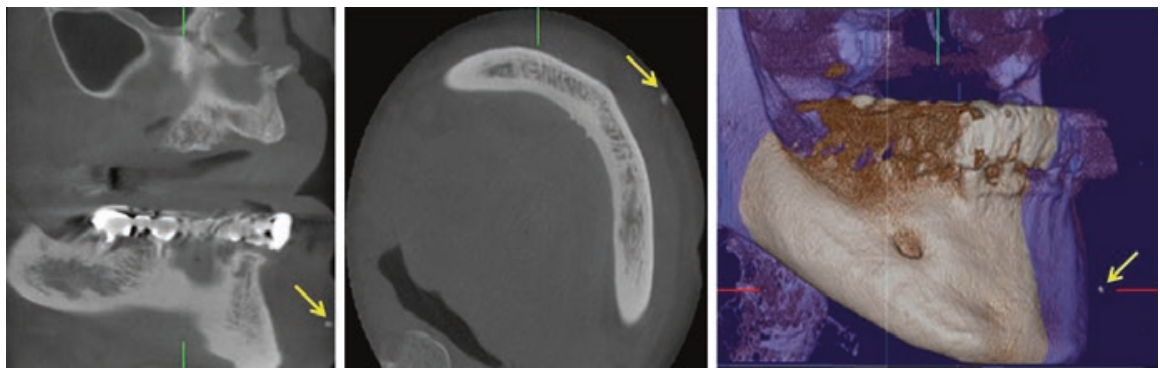

Fig. 11.21 Sagittal, axial, and 3D views of the CBCT scan show a calcified mass in soft tissue, asymptomatic incidental osteoma cutis case

examination of occlusal films, and they found that osteoma cutis can be detected during dental radiographic examinations and calculated their incidence to be $2.2 \%$. But Shigehara et al. [96] reported their incidence was $28 \%$. The most common involved regions include the face, scalp, fingers, cheeks, and lips. Majority of the cases are asymptomatic, and they may detect radiographically as an incidental finding. Radiographically, they appear as smoothly outlined radiopaque formations due to their homogeneous internal structure $[20,97]$. But mostly they are superimposed to the tooth root or dense bone. Imaging by using an intraoral film may be possible only when it is located between cheeks and alveolar process. Or a posteroanterior skull view should be performed while the cheeks blown outward [20]. They are easily visualized by CBCT only when they are carefully examined (Fig. 11.21).

\subsubsection{Calcified Lymph Nodes}

Calcified lymph nodes are one of the calcification of structures in head and neck region. They are often an asymptomatic condition diagnosed accidentally during radiographic examination. Lymph node calcifications can occur in patients with chronic inflammatory diseases or tuberculosis. It can occur also in the patients who have been treated for 
lymphoma [98]. They may be able to detect on palpation. Due to underlying serious conditions, diagnosing and monitoring is crucially important. The most commonly involved nodes are the submandibular and superficial and deep cervical nodes. Radiographically, they present below the inferior border of the mandible and near the mandibular angle, and they usually appear well-defined, lobulated irregularly shaped opacities. The irregular shape is described as "cauliflower-like" [20]. Edwards et al. [90] reported that the incidence of calcified lymph nodes was rare, nearly $0.12 \%$.

\subsubsection{Cysticercosis}

Cysticercosis is a parasitic tissue infection caused by larval cysts of Taenia solium. This affects the central nervous system, muscle, eyes, and skin. Infection is found most often in rural, developing countries where hygiene is poor. Cysticercosis can lead to neurologic and ocular complications, and rarely death. From the first located in the tissues, till death of the larvae, they are not visible in radiographic images. After their death calcification starts in subcutaneous and muscular sites [20]. Muscular cysticercosis appears as "grains of rice" and dot-shaped or well-defined ellipsoidal calcifications and is found incidentally in radiographic images [99].

Life cycle of the Taenia solium is completed in two different hosts including pork and human first as a larva (in the intermediate host) which develops from egg and then as an adult tapeworm (in the definitive host). Infection of Taenia solium can result in two distinct conditions in the human host: taeniasis and cysticercosis [100, 101]. Taeniasis and cysticercosis are highly endemic in developing countries in Latin America, most parts of Asia (including China and the Indian subcontinent), Eastern Europe, and most of Africa. Whereas infection with the adult tapeworm causes intestinal taeniasis, fecal-oral contamination of the larval Taenia solium results in cysticercosis [102]. Cysticercosis in human may affect the brain, muscle, skin, liver, lung, subcutaneous tissue, and heart as well as in the oral and perioral tissues especially in the masticatory muscles where the majority die and become densely calcified [20]. Both T1- and T2-W images show hypointensive area with a null signal due to parasite itself. The nidus due to central location of the parasite can be seen in STIR images (Fig. 11.16). Extraoral conventional imaging modalities such as panoramic or cephalometric images are enough to visualize calcifications. CBCT evaluations easily reveal these calcifications. Calcified masses may be found in the region of masseter and suprahyoid muscles, tongue, buccal mucosa, or lips [20, 103] (Fig. 11.22).

\subsubsection{Phlebolith}

Phleboliths are the deposition of calcium salts which occurred in organized intravascular thrombi by the venous congestion or stagnation. It is always prediction of presence of hemangioma, because they are mostly found in veins, venulae, or the sinusoidal vessels of hemangiomas [20, 104]. Phleboliths are usually multiple; their shape is round or oval, up to $6 \mathrm{~mm}$ in diameter with a smooth periphery. Internal structure commonly has laminated appearance as a bull's eye view [20]. They may 

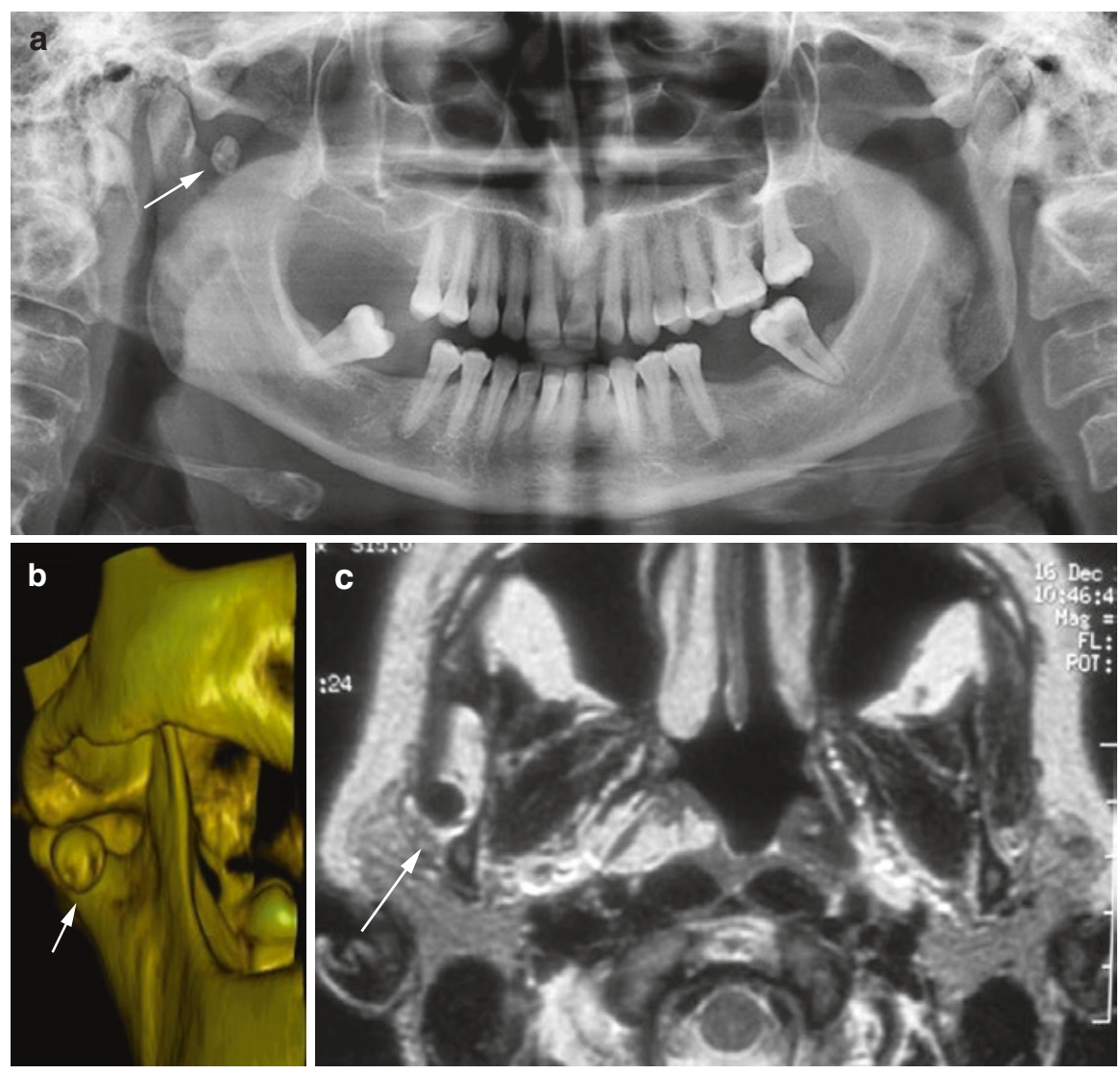

Fig. 11.22 (a) Panoramic image showing calcification around TMJ with limitation of mouth opening symptom, (b) 3D CBCT showing the exact location of the calcification, (c) T1-W MR image showing a signal void area on the master muscle, consistent with maxillofacial cysticercosis

detect by conventional radiographic techniques as well as MR, USG, CT, and CBCT [104]. Differential diagnosis should be made with sialoliths [20].

\subsubsection{Myositis Ossificans}

Myositis ossificans is a benign process characterized by arising bone or bone-like tissue within muscles, tendons, or ligaments. There are two types: localized traumatic or progressive. Localized myositis ossificans can occur as a result of acute or chronic trauma. It may occur not only when applied an intramuscular injection but only heavy muscular strain by sport $[20,104]$. Progressive myositis ossificans is a rare hereditary disease which arises as a result of spontaneous mutation. The mostly involved muscles of maxillofacial area are masseter and sternocleidomastoideus. The less common muscles are medial and lateral pterygoid, buccinator, and temporalis [20]. 
Progressive form also known as fibrodysplasia ossificans progressiva is a rare autosomal dominant genetic disorder and most commonly affects male without any external injury of the muscle [20]. Myositis ossificans circumscripta occur as a result of some traumatic injury to muscle such as acute and chronic trauma, heavy muscular strain, infections, burns, neuromuscular disorders, hemophilia, tetanus, and drug abuse [105]. Masseter and sternocleidomastoid muscles are most commonly affected in the head and neck region [20]. Also it may be localized in other masticatory muscles [106, 107]. MRI appearances depend on the age of the lesion. Early lesions can be misleading before the maturation, however soft tissue may appear with edema. T1-W images show ill-defined isointense images; T2-W shows mostly edema as high signal. The signal intensity may change depending on the localization of the lesion in which central part mostly seen with heterogeneous signal intensity T1-W contrast enhancement is often present. Standard radiographs do not disclose any anomaly in the early stages of myositis ossificans. Typically, they are distant from adjacent bony structures [108]. CT scan examination is more sensitive than radiography for detecting ossification and may also show a central fatty metaplastic area [109].

\subsubsection{Intracranial Calcifications}

Intracranial calcifications can be physiological or pathological. They often occur due to mineral or metal deposition in the blood vessels, glands, cortices, or other structures within the brain [110]. The most common sites include the pineal gland, habenula, choroid plexus, basal ganglia, falx, tentorium, petroclinoid ligaments, and sagittal sinus [111]. According to the literature, intracranial calcifications were common and occur at any age and of any ethnicity [81]. Kwak et al. [112] reported that intracranial calcifications have male predilection. According to literature reports, incidence rates of intracranial calcifications vary from $0.42 \%$ [81] to $71 \%$ [113]. The great differences between incidence rates may be due to many reasons such as sample size, the size of the FOV, radiologic imaging devices, and their different abilities in detecting pathologies.

Since the CBCT gained widespread popularity in dentistry, sensors can easily display larger anatomical fields including intracranial area. Calcified deposits within intracranial region can incidentally detected in most CBCT scans. Medical CTs or CBCT is more effective displaying modalities rather than two-dimensional conventional techniques. It is also reported by Sedghizadeh et al. [110] that CBCT scans have some limitations compared with $\mathrm{CT}$ such as low soft tissue contrast and high noise. CT allows for better identification of anatomical structures or pathologies than CBCT (Fig. 11.23).

\subsubsection{Stylohyoid Ligament Calcification}

The stylohyoid chain consists of two bony structures and a fibrous cord known as the stylohyoid ligament $[114,115]$. Because of congenital factors, trauma, and agerelated factors, this fibrous cord starts to be ossified. Due to its close relationship 

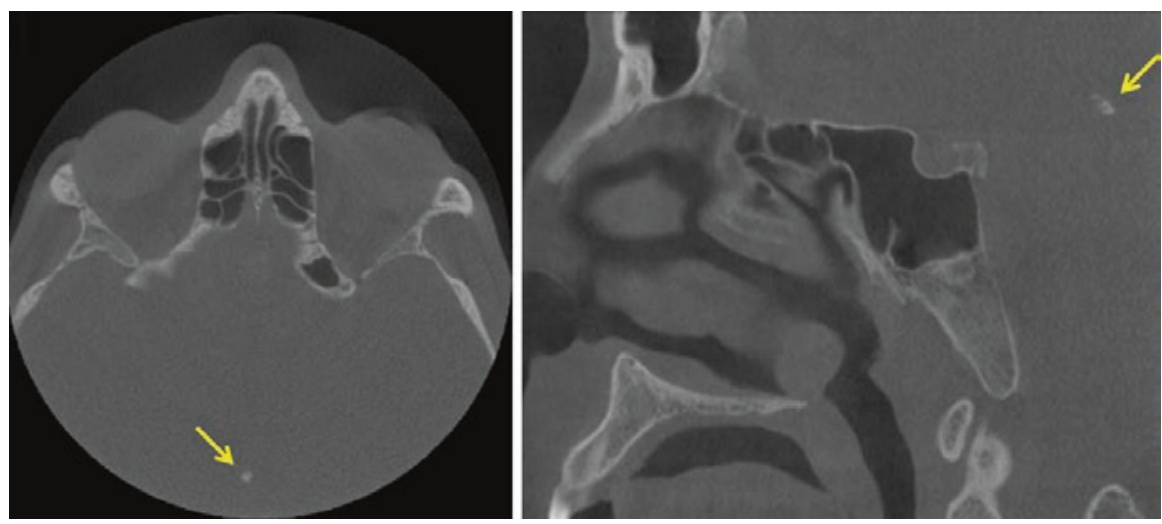

Fig. 11.23 A pineal gland calcification is incidentally found in CBCT examination (arrows)

with some important anatomical structures, ossification or elongation of this complex may lead some symptoms such as dysphagia and head-neck pain. Ossification of the stylohyoid ligament is a common condition which is found as an incidental finding in routine dental radiographic examination [114]. According to literature, incidence rates of stylohyoid ligament ossifications are between $2 \%$ and $30 \%$ [115]. Panoramic radiographs are routinely used in dentistry, and it allows to identify calcified stylohyoid ligament especially in asymptomatic patients. It extends forward from the mastoid region and crosses and superimposed to the ramus toward the hyoid bone. It appears as long, tapering, thin, interrupted by a jointlike junction or a straight structure [20]. Although panoramic radiography has frequently been used to show elongation or ossification of stylohyoid ligament, it also has some disadvantages such as superposition. Hence, CT and CBCT should be used for appropriate evaluation of this structure [115] (Fig. 11.24).

\subsubsection{Arterial Calcifications}

Arterial calcifications are a common consequence of aging and are more frequent in patients with some systemic diseases such as diabetes, dyslipidemia, genetic diseases, and diseases involving disturbances of calcium metabolism. They are a result of the deposition of calcium salts in the cells of the media or intima of the arterial wall [116]. Arterial calcifications have two different forms which identified radiographically and histologically: Mönckeberg's medial calcinosis and calcified atherosclerotic plaque [20]. Calcifications of tunica media of medium-sized arteries are described as Mönckeberg's medial calcinosis. The etiology is not well understood, but it is believed that glucose intolerance, age, sex, osteoporosis, or chronic renal failure is related. Medial calcinosis does not obstruct the lumina of the arteries, so tissue or organ ischemia is not seen [117]. Hence, it is mostly asymptomatic. Only it is clearly seen in three-dimensional imaging modalities and plain radiography techniques as an incidental finding. Radiographically, calcified vessels of Mönckeberg appear as a parallel pair of thin, radiopaque lines which were described 


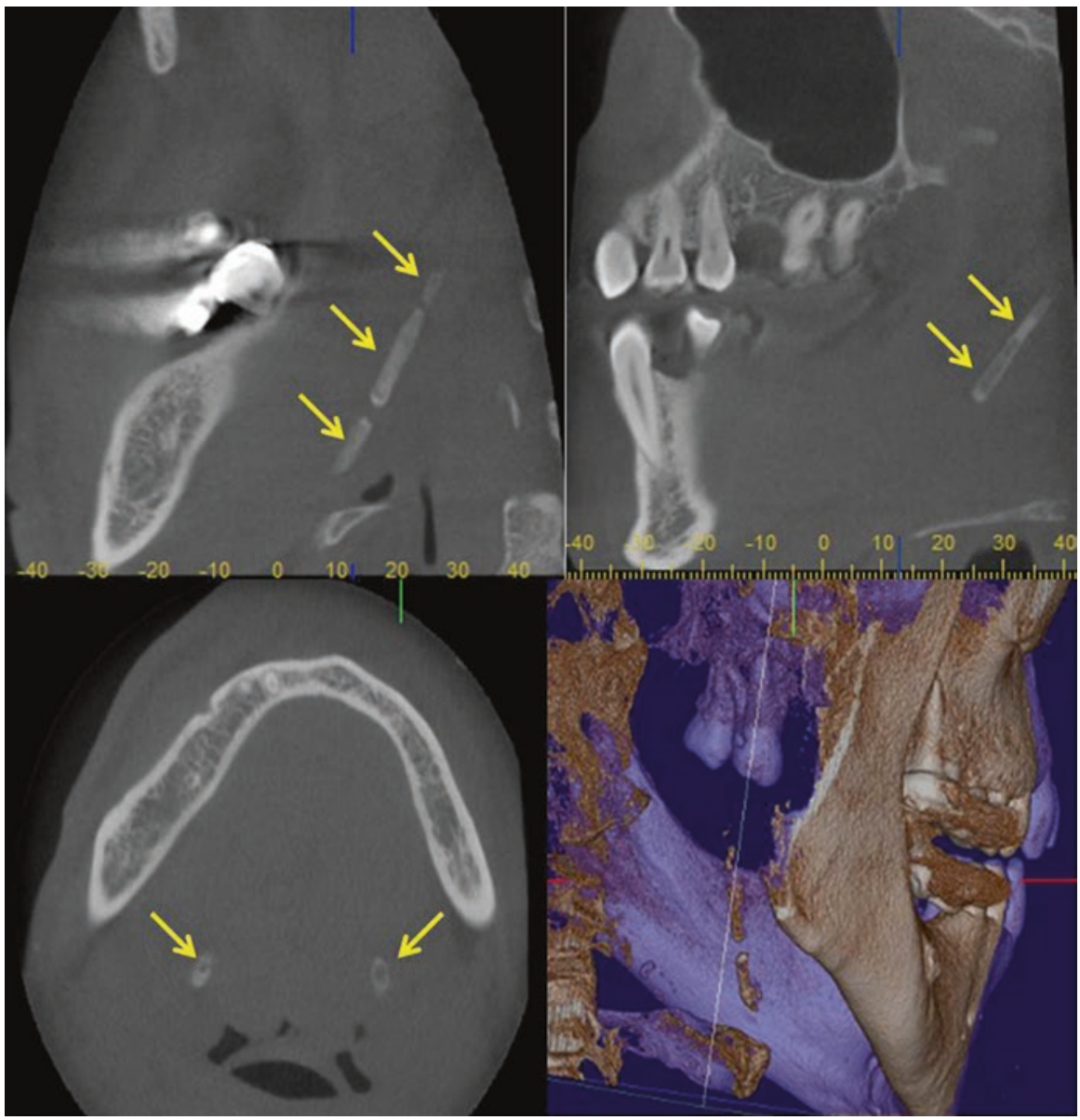

Fig. 11.24 Sagittal, axial, and 3D reconstructed views of elongated stylohyoid ligament (arrows)

as "tram tracks," "pipestem," or "tramline." In cross section, involved vessels can view a circular or ringlike pattern [20, 118].

One another arterial calcification is known as atherosclerosis. It is characterized by deposition of calcium in the atheromatous plaques within the intima of arteries. It causes narrowing the lumen of the affected vessels. The most common location for an atherosclerotic plaque lesion is at the carotid bifurcation; therefore, it may be visible in the panoramic radiograph. It may be seen as a heterogeneous radiopacity at the level of the intervertebral space between C3 and C4. They are usually multiple, unilateral or bilateral, irregular, and sharply defined from the surrounding soft tissues [20]. These plaques have an aspect mostly circular when small and mostly linear or thin rectangular when enlarged. They are usually located posterior to the angle of mandible, approximately at the inferior margin of third cervical vertebra near the hyoid bone [119].

Panoramic radiographs, which are used routinely in dental practice, can often show the presence of carotid atheroma. But authors suggested that angiography was 

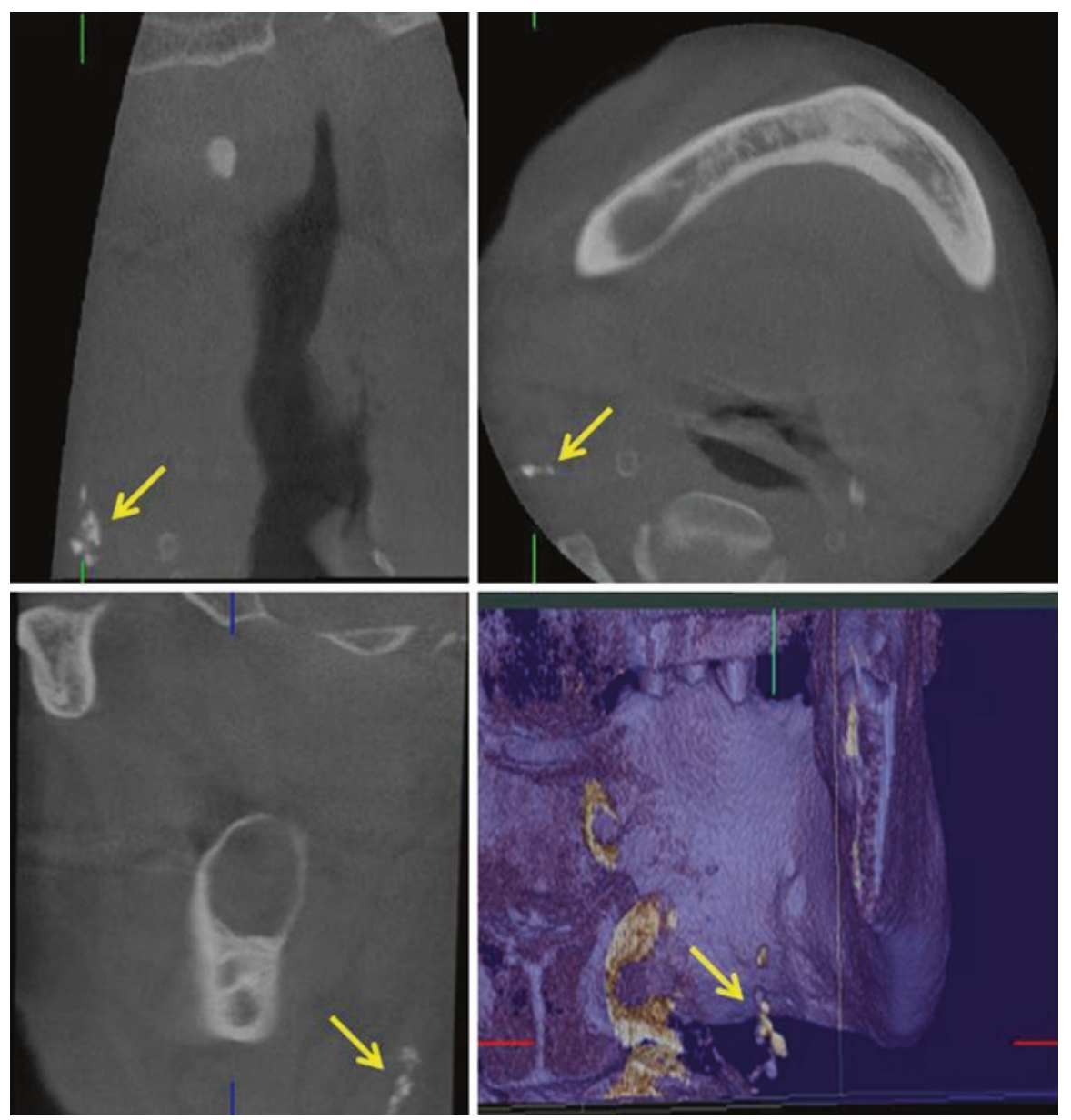

Fig. 11.25 Calcified atherosclerotic plaques are easily visualized in the CBCT scans. Notice that they are multiple-, unilateral-, and irregular-shaped calcified masses (arrows)

considered as a gold standard. Because of its possible complications, color Doppler imaging, also called laser Doppler fluxometry or duplex scan, has been increasingly used to diagnose atheroma because it is a fast, accurate, and painless method of diagnosis [119]. Besides, it is also well known that CBCT or CT reveals precious benefits to detect arterial calcifications [120] (Fig. 11.25).

\subsection{Paranasal Sinus Findings in TMJ Imaging}

The paranasal sinuses are four-paired air-filled spaces which surround the nasal cavity. They consist of maxillary, frontal, and sphenoid sinuses and ethmoid cells. Their infectious diseases can mimic of an odontogenic infection, and practitioners should be careful diagnosing pathologies and familiar with variations [20]. 
Since the first invention of three-dimensional imaging modalities, paranasal sinus evaluations were made by using conventional imaging techniques. As everybody knows, two-dimensional plain radiographic techniques have some limitations such as superimpositions, magnifications, distortions, and low-image quality. Because of these limitations, some pathologies, calcifications, and anatomical variations may be missed [121]. Especially in dentistry, panoramic radiography is routinely used by practitioners to evaluate dentomaxillofacial region. Panoramic radiography allows clinicians to evaluate not only normal anatomy, pathologies, and variations but also TMJ and paranasal sinuses. Evaluation of paranasal sinuses is quite difficult in panoramic images because of superimpositions. To overcome these limitations, CBCT use in dentistry spreads. Due to higher diagnostic sensitivity and specificity levels of CBCT, it became the first imaging tool option by clinicians. It became possible to make further analysis of the findings which could not have detected by conventional imaging modalities [81, 121].

As mentioned in previous chapters, "Any findings on a radiographic image which are not related to the research areas of interest" could be a description of "incidental findings." Paranasal sinus findings are one of these incidental findings. And correct identification of pathologies or variations will reduce further diagnostic assessments [81].

\subsubsection{Maxillary and Sphenoid Sinusitis}

Sinusitis is a condition in which the lining of the paranasal sinuses is inflamed due to an allergen, bacteria, or virus resulting in symptoms. Sinusitis is named depending on the involved sinus and is classified into the three (acute, subacute and chronic) categories based upon symptom duration [20]. Acute sinusitis describes the shortterm (less than 4 weeks) infection or inflammation of the mucosa. Subacute sinusitis is defined as symptoms of 4-12-week duration. If the inflammation persists more than 12 weeks, it is considered chronic $[122,123]$. Signal characteristics depend on the affected regions of the sinuses. In acute stages, on T1-W image due to mucosal thickening, the lesion is isointense to soft tissue, but the fluid shows hypointense areas. On T2-W images both mucosal thickening and fluid can show variable hyperintensity. On contrast-enhanced images, the T1-W images show enhancement only along with the inflamed mucosa (Fig. 11.26).

\subsubsection{Sinus Opacifications}

Sinus opacifications are common finding of paranasal sinuses. Radiopaque appearance of paranasal sinuses occurs in some cases such as mucosal thickening, air-fluid level, mucocele, mucous retention cyst, and total or partial opacifications.

Sinus mucosal thickening also known as mucositis is a common radiographic finding. All paranasal sinuses composed of respiratory epithelium and considered as normal if they are about $0.8-1 \mathrm{~mm}[20,82]$. Besides, some reports have considered mucosal thickening as $\geq 2$ or $\geq 3 \mathrm{~mm}[82,124,125]$. 
Fig. 11.26 T2-W FSE FS coronal image showing maxillary sinusitis with excessive pain symptom of the patient
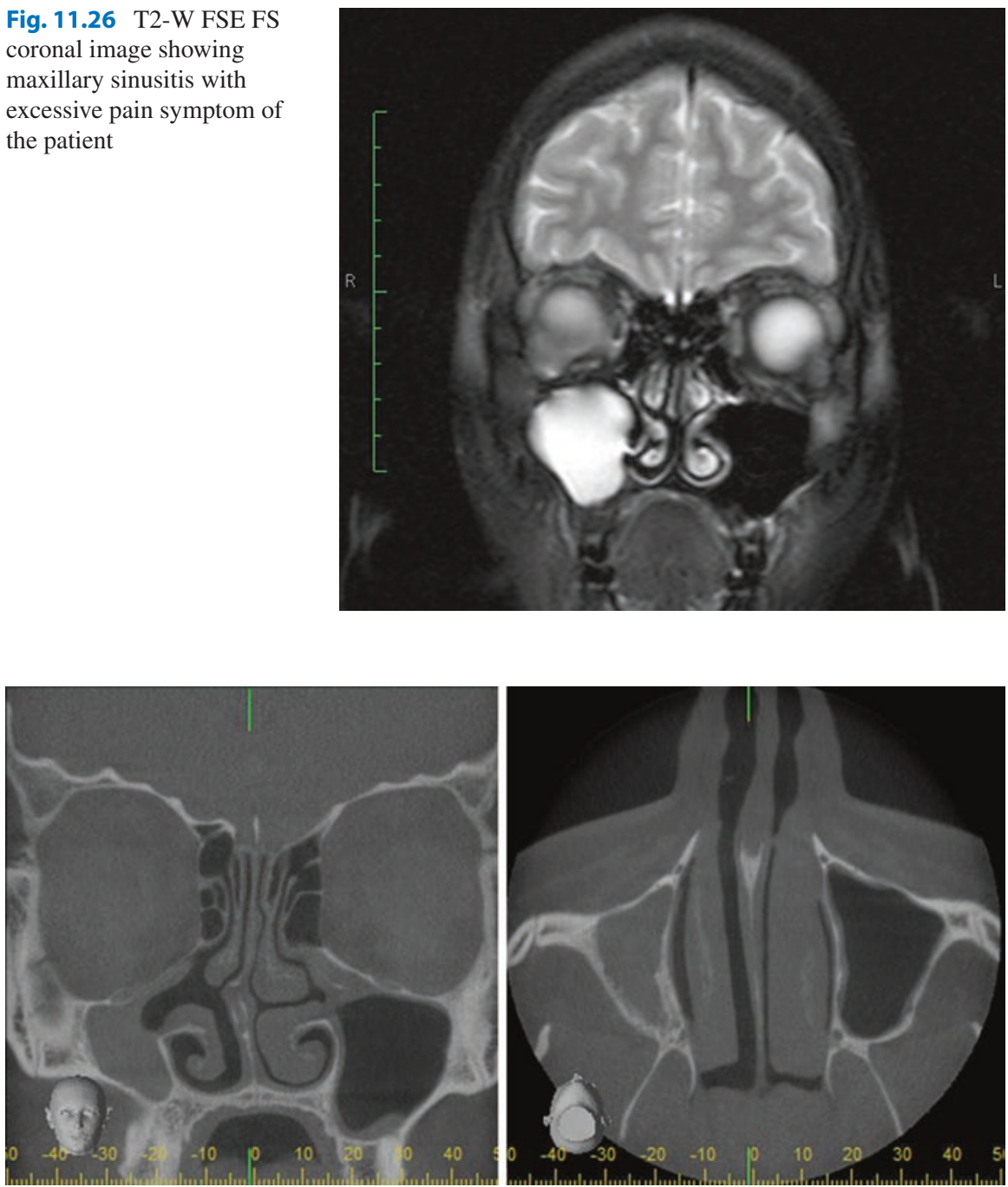

Fig. 11.27 Coronal and axial views of total opacification of right maxillary sinus

Lana et al. [125] reported that mucosal thickening was the most commonly detected lesion. They found mucosal thickening in 313 patients (62.6\%). Avsever et al. [121] reported that incidence was $27.35 \%$.

Normally, sinus mucosa is not visualized especially on conventional radiographic images. Mucosal changes are often discovered as incidental findings on images made for other purposes such as implant planning or TMJ evaluation. When it is possible to visualize, mucosal thickening is seen as well-defined, noncorticated radiopaque band which runs along parallel to the bony wall of the sinus (Fig. 11.27).

The image of thickened sinus mucosa may be uniform or polypoid. In allergic reactions, the mucosa tends to be more lobulated [20] (Fig. 11.28). 

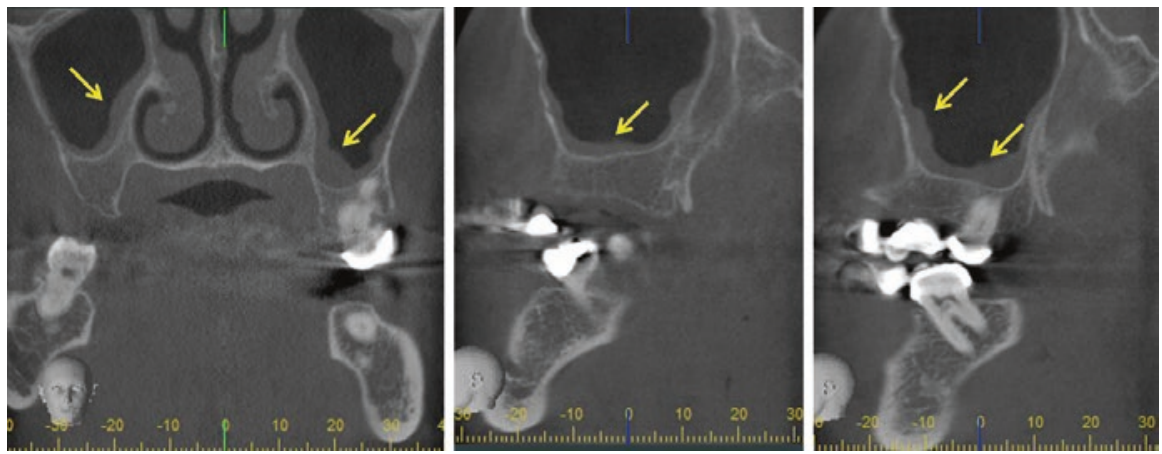

Fig. 11.28 Coronal and sagittal views (right and left) of maxillary sinus with bilateral mucosal thickening (arrows)
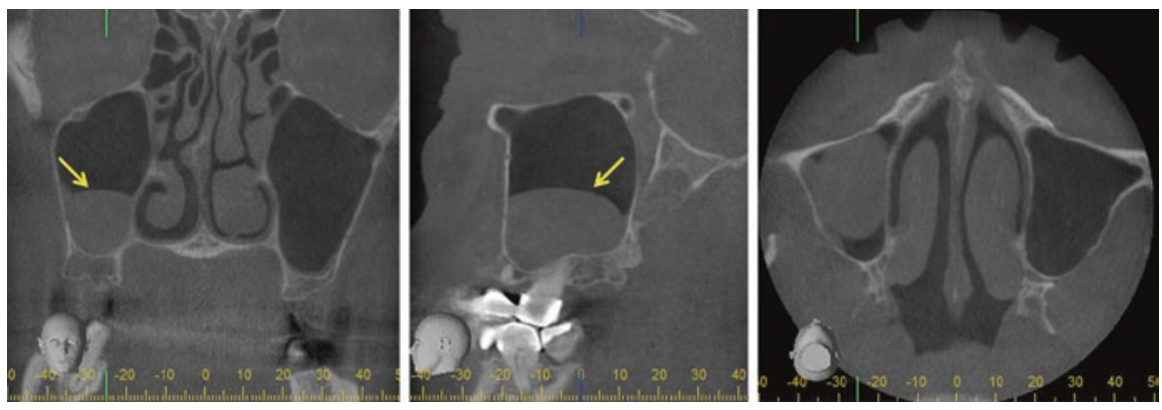

Fig. 11.29 A dome-shaped, well-defined mucous retention cyst in the right maxillary sinus

Mucocele is the lesion which shows certain characteristics such as complete filling of the maxillary sinus and bony expansion. It occurs as a result of blockade of sinus ostium for various reasons such as intra-antral or intranasal inflammation, polyp, or neoplasm. Because of its expansive and destructive character, it is easily diagnosed. Sinus cavity is uniformly radiopaque. Maxillary sinus is rarely affected. Ninety percent of the cases occur in the ethmoid air cells and frontal sinuses. Plain conventional imaging modalities are mostly visualized lesion. But comprehensive evaluation or exact diagnosis is easily made with CT or CBCT [20].

Mucous retention cyst is related to several causes such as humidity, allergens, temperature, or seasonal changes. They are mostly asymptomatic as long as they do not blockade the ostium. They usually visualize as dome-shaped, well-defined, smooth radiopaque masses. They occur mostly on the sinus floor more than the other walls of the sinus (Fig. 11.29). Periapical radiographs of maxillary molar teeth could show a part of mucous retention cyst, but extraoral imaging modalities are most effective. CT or CBCT may be more appropriate for comprehensive evaluation [20]. It will appear as isointense on T1 and hyperintense on T2 images. 

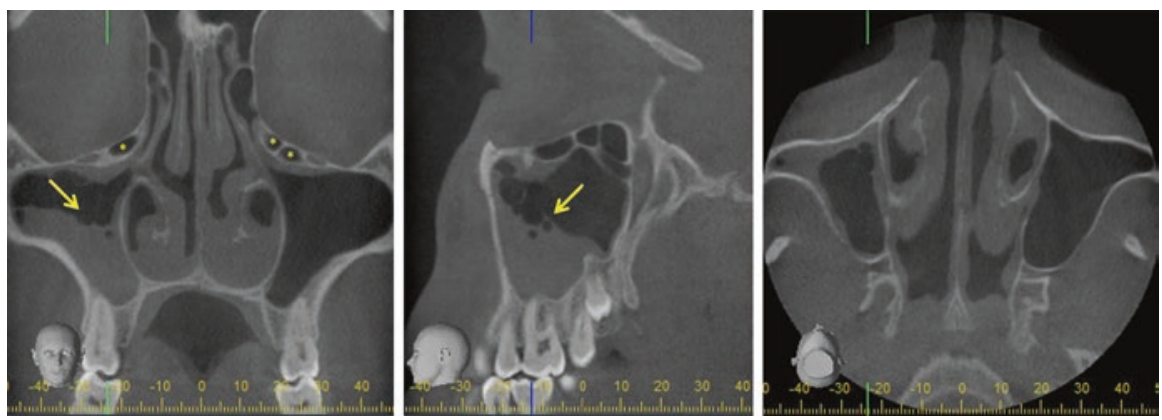

Fig. 11.30 Maxillary sinus with unilateral air-fluid level. Note the clear bubbly foamy-appearing fluid (arrows). Coronal view of CBCT scan also shows bilateral Haller cell (asterisk)

Total or partial opacifications occur in inflammatory conditions. Total opacification blockades the ostium and has some symptoms, but partial opacifications are sometimes asymptomatic. They both do not cause expansion or destruction. Sinus cavity is uniformly radiopaque.

Air-fluid level appears in sinus with its characteristic "bubbly or foamy" appearance (Fig. 11.30). An air-fluid level is the most typical imaging finding of acute sinusitis. It will appear as hypointense on $\mathrm{T} 1$ and hyperintense on $\mathrm{T} 2$ images.

\subsubsection{Hypoplasia and Aplasia}

The maxillary sinuses are the first developed among paranasal sinuses and lasts its growth at the end of puberty $[126,127]$. Hypoplasia is underdevelopment or incomplete development of a tissue or organ. Aplasia is defined as absence of organ or tissue. Etiology of hypoplasia or aplasia includes both embryological and acquired causes like trauma or infection [128].

Hypoplasia of the paranasal sinuses is a rare condition [129]. The frontal and sphenoid sinuses are most frequently involved [130]. The incidence of maxillary sinus hypoplasia ranges between 1.5 and 10\% [129]. Hypoplasia of the maxillary sinuses occurs unilaterally in about $1.7 \%$ of patients and bilaterally in $7.2 \%$. Hypoplasia of the frontal sinus is a common normal variant, and aplasia of the frontal sinuses is noted in approximately $4 \%$ of the population [20].

Conventional radiographs such as panoramic radiography, Water's projection, and intraoral radiography are routinely used in evaluation of maxillary sinus. Because of the complex anatomy of the dentomaxillofacial region, it is difficult to visualize important anatomical structures due to the superimposition [124]. Maxillary sinus hypoplasia can be misdiagnosed with mucosal thickening in infectious disease or neoplasms involving the sinus in conventional radiographs. Maxillary sinus hypoplasia can be seen as a partial opacification, and aplasia appears 

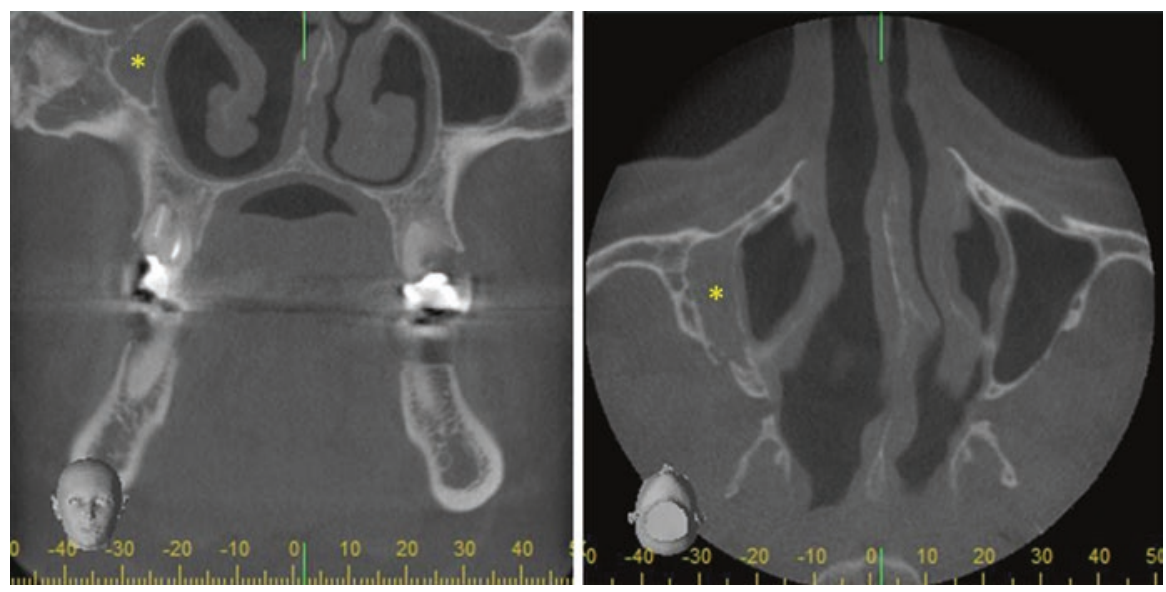

Fig. 11.31 Coronal and axial views of maxillary sinus hypoplasia. It is also seen a total opacification (asterisk)

as a total opacification. CT/CBCT examination is the ideal method for detecting this anatomical variation. Radiological diagnosis of maxillary sinus hypoplasia and aplasia is important to prevent possible complications during endoscopic sinus surgery, such as causing potential harm to the orbit [131] (Fig. 11.31).

\subsubsection{Haller Cell}

Haller cell is an anatomical variation which is located lateral to the maxilloethmoidal suture along the inferomedial orbital floor. They are also known as infraorbital ethmoidal air cells [132]. The prevalence of Haller cells is reported to be between $2 \%$ and $68 \%$ in the literature $[133,134]$. Some reports have shown the Haller cells with larger than $3 \mathrm{~mm}$ in diameter, have a precious relationship with maxillary sinusitis $[132,135,136]$.

With the increasing popularity of endoscopic sinus surgery, visualization of Haller cell or any anatomical variations became important. Infraorbital ethmoid cells may be visualized by a variety of imaging methods that show a view of the maxillary sinus. Plain radiography or three-dimensional imaging modalities which were performed to evaluate TMJ commonly visualize infraorbital ethmoid cells. CT and CBCT are commonly used for imaging infraorbital ethmoid cells, and they are frequently seen as incidental findings in CT/CBCT examination of paranasal sinuses. It is also possible to detect them by panoramic radiographs [137].

\subsubsection{Onodi Air Cell}

Sphenoethmoidal air cell, also known as the Onodi air cell, is an anatomic variant of the most posterior ethmoid cell that pneumatized superiorly and laterally to the 
Fig. 11.32 Unilateral Onodi cell (asterisk)

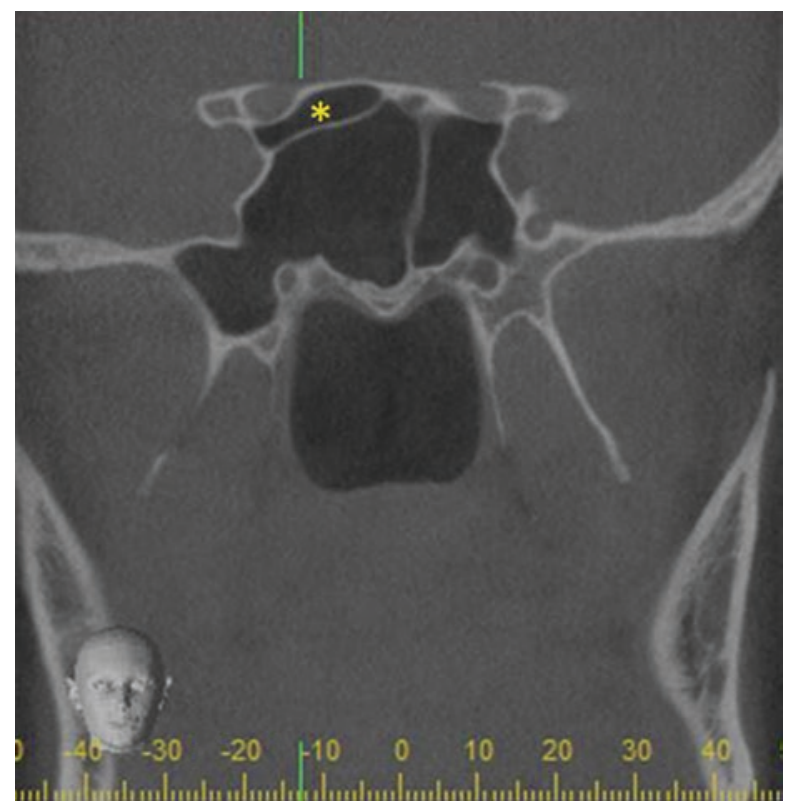

sphenoid sinus and is in close relation to the optic nerve and internal carotid artery. Their importance is the close relationship with optic nerve and internal carotid artery. The damage of these structures causes some important complications during sinus surgery. They are usually asymptomatic, unless complicated by sinus disease. The incidence of Onodi cells on imaging studies is between $4.6 \%$ and 65.6\% [121, 138]. The possible causes of the variety of prevalence are racial factors and differences of chosen imaging modalities. Using endoscopic dissection, Kainz and Stammberger [139] reported its prevalence was $42 \%$.

Onodi cells are often discovered as incidental findings on radiographic images. CT/CBCT scanning of paranasal sinuses provides valuable information in assessing extent of the air cell and detailed anatomy prior to endoscopic sinus surgery (Fig. 11.32). It is also suggested that, among examination/imaging methods, nasal endoscopy is more sensitive than CT in identifying an Onodi cell [140].

\subsubsection{Concha Bullosa}

Concha bullosa is generally defined as the pneumatization of the middle turbinate in the nose. However, pneumatization may also be seen in the superior and inferior turbinate [141]. In majority of cases, these variants are asymptomatic. Sometimes it is associated with deviation of the nasal septum. Although it was first described as a rare anatomical variation, Smith et al. [142] reported that incidence rate was $67.5 \%$. In addition to radiologic reports, clinical data from Goldman [143], who encountered pneumatization in $80 \%$ of resected middle turbinates from patients undergoing ethmoidectomy for chronic sinusitis, suggested a higher prevalence. 
Fig. 11.33 Bilateral concha bullosa (asterisk)

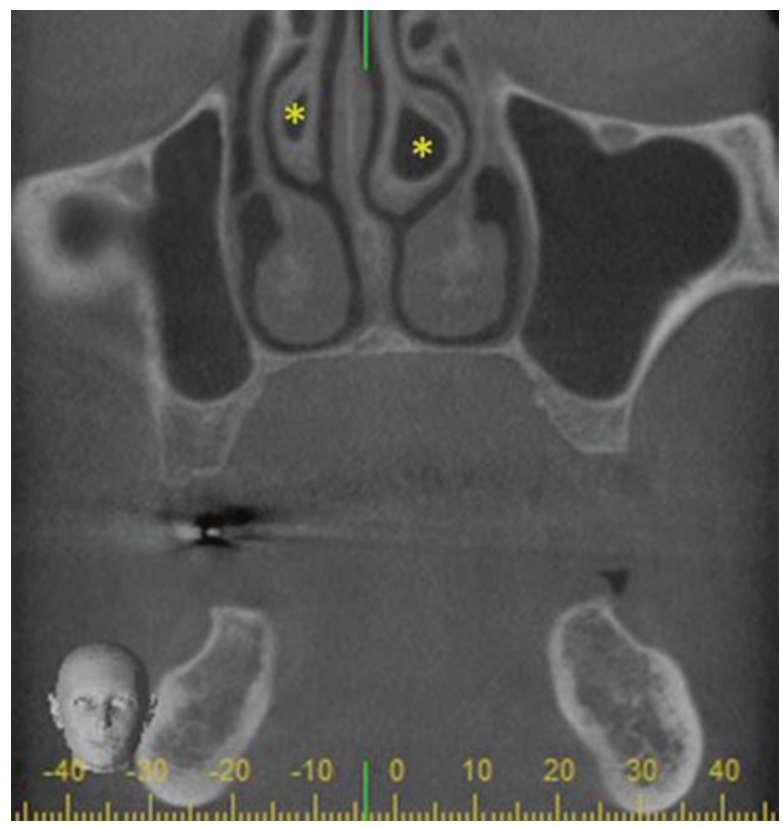

Coronal plane CT/CBCT imaging was used to critically analyze the middle turbinate pneumatization (Fig. 11.33).

\subsubsection{Agger Nasi}

Agger nasi cells are the most anterior ethmoid air cells and are located anterior, lateral, and inferior to the frontal recess. Presence of some anatomical variations such as Agger nasi may affect the functional drainage pathways and predispose for sinus disease. The recognition of sinonasal anatomic variations is important for the avoidance of surgical complications [144]. The prevalence of Agger nasi cells has previously been reported as wide ranging. In a CBCT examination, Avsever et al. [121] found Agger nasi cells in $2.88 \%$ of specimens examined; however, Bolger et al. [145] noted this cell type in $98.5 \%$ of their sample. They should not be confused with Haller cells which located along the medial floor of the orbit.

Imaging of Agger nasi with standard sinus radiographic techniques may be failed because of their limitations. Endoscopic visualization is gold standard. Highresolution multisliced multiplanar CT or CBCT scans provide valuable information about anatomical structures or variations [121] (Fig. 11.34).

\subsubsection{Accessory Ostium}

The maxillary sinuses communicate with the nasal cavity by the ostium, approximately $3-6 \mathrm{~mm}$ in diameter and positioned under the posterior aspect of the middle 

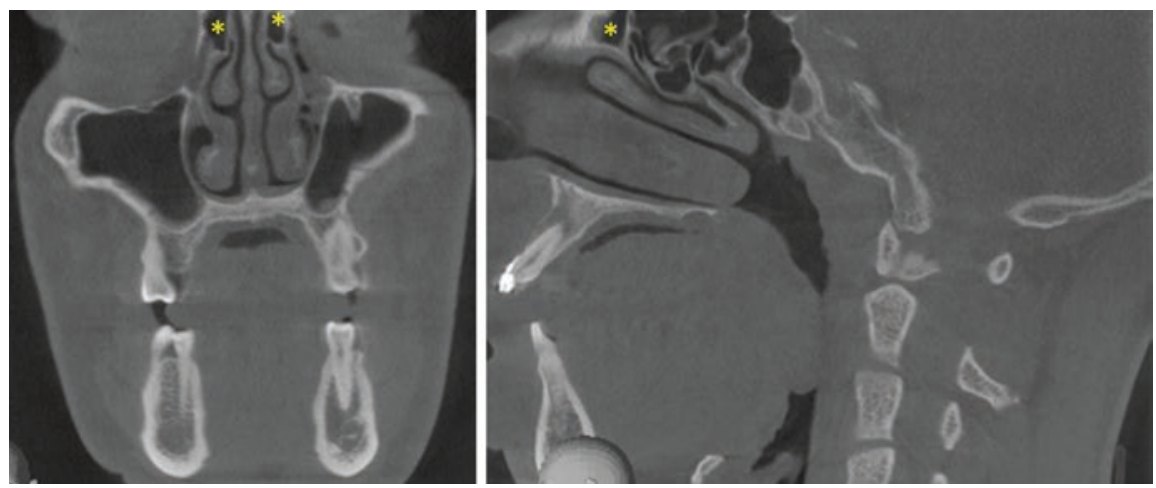

Fig. 11.34 Coronal and sagittal views show bilateral Agger nasi cells (asterisk)
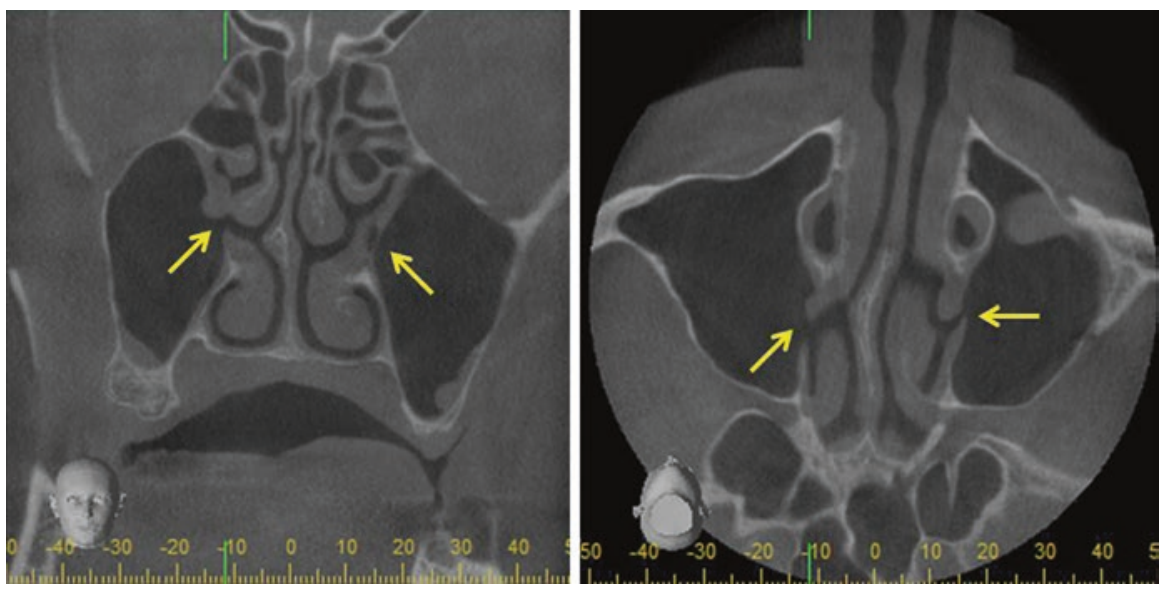

Fig. 11.35 Coronal and axial views of accessory maxillary sinus ostium (arrows)

concha [20]. Accessory maxillary ostium was another variation seen in nearly threefourths of the cases which opened into membranous meatus inferior to the uncinate process [146]. It is a rare variation of paranasal sinuses. The prevalence of accessory ostium has been reported between $0 \%$ and 43\% [147-150]. According to CT evaluations in a study, Earwalker [147] reported its prevalence as 14\%. Jog and McGarry [148] used a flexible endoscope to investigate accessory ostium, and they reported the prevalence as $4 \%$.

Many radiographic imaging techniques have been employed to study the maxillary sinus. Due to its limitations, plain conventional radiographic techniques are not able to visualize the paranasal variations such as accessory ostium. Obtaining a three-dimensional view using CT is a more accurate method to evaluate the maxillary sinus. In addition, CBCT becomes the first choice to evaluate dentomaxillary area because of its advantages [151] (Fig. 11.35). 
Acknowledgments The authors would like to thank to Dr. Murat İçen for providing maxillofacial cysticercosis images.

\section{References}

1. Orhan K, Gorurgoz C, Akyol M, Ozarslanturk S, Avsever H. An anatomical variant: evaluation of accessory canals of the canalis sinuosus using CBCT. Folia Morphol (Warsz). 2018. https://doi.org/10.5603/FM.a2018.0003.

2. Kini YK, Kharkar VR, Rudagi BM, Kalburge JV. An unusual occurrence of epidermoid cyst in the buccal mucosa: a case report with review of literature. J Maxillofac Oral Surg. 2013;12(1):90-3.

3. Osborn AG, Preece MT. Intracranial cysts: radiologic-pathologic correlation and imaging approach. Radiology. 2006;239(3):650-64.

4. Park TW, Kim JK, Kim JR. Giant epidermal cyst in the posterior neck developing over 40 years: a case report. Exp Ther Med. 2014;7(1):287-9.

5. Zhou F, Yang Z, Zhu W, Chen L, Song J, Quan K, Li S, Li P, Pan Z, Liu P, Mao Y. Epidermoid cysts of the cavernous sinus: clinical features, surgical outcomes, and literature review. J Neurosurg. 2017;22:1-11.

6. Hu XY, Hu CH, Fang XM, Cui L, Zhang QH. Intraparenchymal epidermoid cysts in the brain: diagnostic value of MR diffusion-weighted imaging. Clin Radiol. 2008;63(7):813-8.

7. Janarthanam J, Mahadevan S. Epidermoid cyst of submandibular region. J Oral Maxillofac Pathol. 2012;16(3):435-7.

8. Garg K, Borkar SA, Kale SS, Sharma BS. Spinal arachnoid cysts - our experience and review of literature. Br J Neurosurg. 2017;31(2):172-8.

9. Logan C, Asadi H, Kok HK, Looby S, O'Hare A, Tornton J, Brennan P. Arachnoid cysts common and uncommon clinical presentations and radiological features. J Neuroimaging Psychiatry Neurol. 2016;1(2):79-84.

10. Nadgir R, Yousem DM. Neuroradiology: the requisites. 4th ed. Philadelphia: Mosby/Elsevier; 2017.

11. Righi S, Boffano P, Pateras D, Malvè L, Chiodo D, Boson M. Thornwaldt cysts. J Craniofac Surg. 2014;25(5):456-7.

12. Weissman JL. Thornwaldt cysts. Am J Otolaryngol. 1992;13(6):381-5.

13. Ford WJ, Brooks BS, el Gammal T. Thornwaldt cyst: an incidental MR diagnosis. AJNR Am J Neuroradiol. 1987;8(5):922-3.

14. Brennan B. Nasopharyngeal carcinoma. Orphanet J Rare Dis. 2006;26:1-23.

15. Chua MLK, Wee JTS, Hui EP, Chan ATC. Nasopharyngeal carcinoma. Lancet. 2016;387(10022):1012-24.

16. Hsu WM, Wang AG. Nasopharyngeal carcinoma with orbital invasion. Eye (Lond). 2004;18(8):833-8.

17. Shanmugaratnam K, Sobin LH. The World Health Organization histological classification of tumours of the upper respiratory tract and ear. A commentary on the second edition. Cancer. 1993;71(8):2689-97.

18. Hermans R. Head and neck cancer imaging. 1st ed. Berlin: Springer; 2006.

19. Bailey BJ. Head and neck surgery otolaryngology. 3rd ed. Philadelphia: Lippincott Williams and Wilkins; 2001.

20. White CS, Pharoah JM, editors. Oral radiology principles and interpretation. 7th ed. St. Louis: Elsevier; 2014.

21. Rong X, Zhu Q, Ji H, Li J, Huang H. Differentiation of pleomorphic adenoma and Warthin's tumor of the parotid gland: ultrasonographic features. Acta Radiol. 2014;55(10):1203-9.

22. Dumitriu D, Dudea SM, Botar-Jid C, Băciuţ G. Ultrasonographic and sonoelastographic features of pleomorphic adenomas of the salivary glands. Med Ultrason. 2010;12(3):175-83. 
23. Klintworth N, Mantsopoulos K, Zenk J, Psychogios G, Iro H, Bozzato A. Sonoelastography of parotid gland tumours: initial experience and identification of characteristic patterns. Eur Radiol. 2012;22(5):947-56.

24. Weidner N, Cote R, Suster S, Weiss L. Modern surgical pathology. 2nd ed. Philadelphia: Saunders; 2009.

25. Sepúlveda I, Platín E, Spencer ML, Mucientes P, Frelinghuysen M, Ortega P, Ulloa D. Oncocytoma of the parotid gland: a case report and review of the literature. Case Rep Oncol. 2014;7(1):109-16.

26. Lee YY, Wong KT, King AD, Ahuja AT. Imaging of salivary gland tumours. Eur J Radiol. 2008;66(3):419-36.

27. Spiro RH. Salivary neoplasms: overview of a 35-year experience with 2,807 patients. Head Neck Surg. 1986;8(3):177-84.

28. Liu XW, Xie CM, Li H, Zhang R, Geng ZJ, Mo YX, Zhao J, Cai MY, Lv YC, Wu $\mathrm{PH}$. Nasopharyngeal adenoid cystic carcinoma: magnetic resonance imaging features in ten cases. Chin J Cancer. 2012;31(1):19-28.

29. Rzepakowska A, Zwierzyńska K, Osuch-Wójcikiewicz E, Niemczyk K. Lymphoid tissue neoplasms in the neck region - epidemiological and clinical analysis over 15 years. Otolaryngol Pol. 2017;71(3):1-9.

30. Weber AL, Rahemtullah A, Ferry JA. Hodgkin and non-Hodgkin lymphoma of the head and neck: clinical, pathologic, and imaging evaluation. Neuroimaging Clin N Am. 2003;13(3):371-92.

31. Ying M, Bhatia KS, Lee YP, Yuen HY, Ahuja AT. Review of ultrasonography of malignant neck nodes: greyscale, Doppler, contrast enhancement and elastography. Cancer Imaging. 2014;13(4):658-69.

32. Louis DN, Perry A, Reifenberger G, von Deimling A, Figarella-Branger D, Cavenee WK, Ohgaki H, Wiestler OD, Kleihues P, Ellison DW. The 2016 World Health Organization classification of tumors of the central nervous system: a summary. Acta Neuropathol. 2016;131(6):803-20.

33. Yue JJ, Guyer RD, Johnson JB, Khoo LT, Hochschuler SH. The comprehensive treatment of the aging spine minimally invasive and advanced techniques. 1st ed. Philadelphia: Elseiver; 2011.

34. Haaga JR, Dogra VS, Forsting M, Gilkeson RC, Kwon Ha H, Sundaram M. CT and MRI of the whole body. 5th ed. Philadelphia: Mosby Elsevier; 2009.

35. Niiro M, Yatsushiro K, Nakamura K, Kawahara Y, Kuratsu J. Natural history of elderly patients with asymptomatic meningiomas. J Neurol Neurosurg Psychiatry. 2000;68(1): $25-8$.

36. Surov A, Gottschling S, Mawrin C, Prell J, Spielmann RP, Wienke A, Fiedler E. Diffusionweighted imaging in meningioma: prediction of tumor grade and association with histopathological parameters. Transl Oncol. 2015;8(6):517-23.

37. Schlosser RJ, Woodworth BA, Gillespie MB, Day TA. Endoscopic resection of sinonasal hemangiomas and hemangiopericytomas. ORL J Otorhinolaryngol Relat Spec. 2006;68(2):69-72.

38. Nikiforova L, Sapundzhiev N, Kolova P, Boyadzhiev G, Bradley P. Fulminant hemangiopericytoma of the larynx - a case report and a review of the literature. Braz J Otorhinolaryngol. 2017; pii: S1808-8694(17)30073.

39. Batsakis JG, Rice DH. The pathology of head and neck tumors: vasoformative tumors, part 9B. Head Neck Surg. 1981;3(4):326-39.

40. Koch M, Nielsen GP, Yoon SS. Malignant tumors of blood vessels: angiosarcomas, hemangioendotheliomas, and hemangioperictyomas. J Surg Oncol. 2008;97:321-9.

41. Persky M, Tran T. Acquired vascular tumors of the head and neck. Otolaryngol Clin North Am. 2018;51(1):255-74.

42. Becker M, Stefanelli S, Rougemont AL, Poletti PA, Merlini L. Non-odontogenic tumors of the facial bones in children and adolescents: role of multiparametric imaging. Neuroradiology. 2017;59(4):327-42. 
43. Maniu A, Harabagiu O, Perde Schrepler M, Cătană A, Fănuţă B, Mogoantă CA. Molecular biology of cholesteatoma. Romanian J Morphol Embryol. 2014;55(1):7-13.

44. Preciado DA. Biology of cholesteatoma: special considerations in pediatric patients. Int $\mathbf{J}$ Pediatr Otorhinolaryngol. 2012;76(3):319-21.

45. Thompson LD. Update from the 4th edition of the world health organization classification of head and neck tumours: tumours of the ear. Head Neck Pathol. 2017;11(1):78-87.

46. Lingam RK, Connor SEJ, Casselman JW, Beale T. MRI in otology: applications in cholesteatoma and Ménière's disease. Clin Radiol. 2018;73(1):35-44.

47. Widmann G, Henninger B, Kremser C, Jaschke W. MRI sequences in head \& neck radiology - state of the art. Rofo. 2017;189(5):413-22.

48. Vaid S, Kamble Y, Vaid N, Bhatti S, Rawat S, Nanivadekar A, Karmarkar S. Role of magnetic resonance imaging in cholesteatoma: the Indian experience. Indian J Otolaryngol Head Neck Surg. 2013;65(Suppl 3):485-92.

49. Lincot J, Veillon F, Riehm S, Babay N, Matern JF, Rock B, Dallaudière B, Meyer N. Middle ear cholesteatoma: compared diagnostic performances of two incremental MRI protocols including non-echo planar diffusion-weighted imaging acquired on 3T and 1.5T scanners. J Neuroradiol. 2015;42(4):193-201.

50. Neville BW, Damm DD, Allen CM, Bouquot JE, editors. Oral and maxillofacial pathology. Pennsylvania: W. B. Saunders; 2002.

51. Orhan K, Kocyigit D, Kisnisci R, Paksoy CS. Rhinolithiasis: an uncommon entity of the nasal cavity. Oral Surg Oral Med Oral Pathol Oral Radiol Endod. 2007;01:e28-32.

52. Orhan K, Orhan AI, Oz U, Pekiner FN, Delilbasi C. Misdiagnosed fibrosarcoma of the mandible mimicking temporomandibular disorder: a rare condition. Oral Surg Oral Med Oral Pathol Oral Radiol Endod. 2007;104(4):e26-9.

53. Sapp JP, Eversole LR, Wysocki GP, editors. Contemporary oral and maxillofacial pathology. St. Louis: Mosby; 2004. p. 302-3.

54. Gobetti JP, Türp JC. Fibrosarcoma misdiagnosed as a temporomandibular disorder: a cautionary tale. Oral Surg Oral Med Oral Pathol Oral Radiol Endod. 1998;85(4):404-9.

55. Wang H, Nie P, Dong C, Li J, Huang Y, Hao D, Xu W. CT and MRI findings of soft tissue adult fibrosarcoma in extremities. Biomed Res Int. 2018;2018:1-7. Article ID 6075705, 7 pages.

56. Nadol JB, Eavey RD. Acute and chronic mastoiditis: clinical presentation, diagnosis, and management. Curr Clin Top Infect Dis. 1995;15:204-9.

57. Orhan K, Nishiyama H, Tadashi S, Shumei M, Furukawa S. MR of 2270 TMJs: prevalence of radiographic presence of otomastoiditis in temporomandibular joint disorders. Eur J Radiol. 2005;55(1):102-7.

58. Som MP, Curtin DH. Head and neck imaging. St. Louis: Mosby; 2011.

59. Chien JH, Chen YS, Hung IF, Hsieh KS, Wu KS, Cheng MF. Mastoiditis diagnosed by clinical symptoms and imaging studies in children: disease spectrum and evolving diagnostic challenges. J Microbiol Immunol Infect. 2012;45(5):377-81.

60. Debnath J, Ravikumar R, Sharma V, Senger KP, Maurya V, Singh G, Sharma P, Khera A, Singh A. 'Empty sella' on routine MRI studies: an incidental finding or otherwise? Med J Armed Forces India. 2016;72(1):33-7.

61. Guitelman M, Garcia Basavilbaso N, Vitale M, Chervin A, Katz D, Miragaya K, Herrera J, Cornalo D, Servidio M, Boero L, Manavela M, Danilowicz K, Alfieri A, Stalldecker G, Glerean M, Fainstein Day P, Ballarino C, Mallea Gil MS, Rogozinski A. Primary empty sella (PES): a review of 175 cases. Pituitary. 2013;16(2):270-4.

62. Agarwal JK, Sahay RK, Bhadada SK, Reddy VS, Agarwal NK. Empty sella syndrome. J Indian Acad Clin Med. 2001;2(3):198-202.

63. Chiloiro S, Giampietro A, Bianchi A, Tartaglione T, Capobianco A, Anile C, De Marinis L. Diagnosis of endocrine disease: primary empty Sella: a comprehensive review. Eur J Endocrinol. 2017;177(6):R275-85.

64. Narula N, Siddiqui F, Katyal N, Avula A, Chalhoub M. Internal carotid artery dissection with lidocaine nerve block injection trauma: a rare case report. Cureus. 2018;10(1):e2027. 
65. Provenzale JM. Dissection of the internal carotid and vertebral arteries: imaging features. AJR Am J Roentgenol. 1995;165(5):1099-104.

66. Rodallec MH, Marteau V, Gerber S, Desmottes L, Zins M. Craniocervical arterial dissection: spectrum of imaging findings and differential diagnosis. Radiographics. 2008;28(6):1711-28.

67. English SW, Passe TJ, Lindell EP, Klaas JP. Multiple cranial neuropathies as a presentation of spontaneous internal carotid artery dissection: a case report and literature review. J Clin Neurosci. 2018;50:129-31.

68. Truwit CL. Venous angioma of the brain: history, significance, and imaging findings. AJR Am J Roentgenol. 1992;159(6):1299-307.

69. Wiggins RH, Harnsberger HR, Salzman KL, Shelton C, Kertesz TR, Glastonbury CM. The many faces of facial nerve schwannoma. AJNR Am J Neuroradiol. 2006;27(3):694-9.

70. Garrity JA, Henderson JW. Henderson's orbital tumors. 4th ed. New York: Lippincott Williams and Wilkins; 2007.

71. Younis RT, Gross CW, Lazar RH. Schwannomas of the paranasal sinuses. Case report and clinicopathologic analysis. Arch Otolaryngol Head Neck Surg. 1991;117(6):677-80.

72. Mesolella M, Cimmino M, Di Martino M, Criscuoli G, Albanese L, Galli V. Tonsillolith. Case report and review of the literature. Acta Otorhinolaryngol Ital. 2004;24(5):302-7.

73. Chan J, Rashid M, Karagama Y. An unusual case of a tonsillolith. Case Rep Med. 2012;2012:587503.

74. Dykes M, Izzat S, Pothula V. Giant tonsillolith - a rare cause of dysphagia. J Surg Case Rep. 2012;4:4.

75. de Moura MD, Madureira DF, Noman-Ferreira LC, Abdo EN, de Aguiar EG, Freire AR. Tonsillolith: a report of three clinical cases. Med Oral Patol Oral Cir Bucal. 2007;12(2):E130-3.

76. Alfayez A, Albesher MB, Alqabasani MA. A giant tonsillolith. Saudi Med J. 2018;39(4): $412-4$.

77. Valdez TA, Vallejo JG. Infectious diseases in pediatric otolaryngology. 1st ed. Basel: Springer; 2016.

78. Centurion BS, Imada TS, Pagin O, Capelozza AL, Lauris JR, Rubira-Bullen IR. How to assess tonsilloliths and styloid chain ossifications on cone beam computed tomography images. Oral Dis. 2013;19:473-8.

79. Oda M, Kito S, Tanaka T, Nishida I, Awano S, Fujita Y, et al. Prevalence and imaging characteristics of detectable tonsilloliths on 482 pairs of consecutive CT and panoramic radiographs. BMC Oral Health. 2013;13:54.

80. Omami G. Soft tissue calcification in oral and maxillofacial imaging: a pictorial review. Int J Dentistry Oral Sci. 2016;03(4):219-24.

81. Altındağ A, Avsever H, Borahan O, Akyol M, Orhan K. Incidental findings in cone-beam computed tomographic images: calcifications in head and neck region. Balk J Dent Med. 2017;21:100-7.

82. Price JB, Thaw KL, Tyndall DA, Ludlow JB, Padilla RJ. Incidental findings from cone beam computed tomography of the maxillofacial region: a descriptive retrospective study. Clin Oral Implants Res. 2012;23:1261-8.

83. Bar T, Zagury A, London D, Shacham R, Nahlieli O. Calcifications simulating sialolithiasis of the major salivary glands. Dentomaxillofac Radiol. 2007;36(1):59-62.

84. Siddiqui SJ. Sialolithiasis: an unusually large submandibular salivary stone. Br Dent J. 2002;193(2):89-91.

85. Nass Duce M, Talas DU, Ozer C, Yildiz A, Apaydin FD, Ozgür A. Antrolithiasis: a retrospective study. J Laryngol Otol. 2003;117:637-40.

86. Senkal HA, Süslü AE, Ünal ÖF. A rare cause of rhinolithiasis: ectopic. Int J Pediatr Otorhinolaryngol. 2006;70:2129.

87. Karjodkar FR. Textbook of dental and maxillofacial radiology. 2nd ed. Mumbai: Jaypee Brothers Medical; 2009.

88. Ozarslanturk S, Ozturk HP, Senel B, Avsever H, Ozen T. What surprises lie beneath a panoramic radiograph in dental implant planning. Dentistry Adv Res. 2018; DTAR-148. 
89. Orhan K, Kocyigit D, Kisnisci R, Paksoy CS. Rhinolithiasis: an uncommon entity of the nasal cavity. Oral Surg Oral Med Oral Pathol Oral Radiol Endod. 2006;101(2):e28-32.

90. Edwards R, Alsufyani N, Heo G, Flores-Mir C. The frequency and nature of incidental findings in large-field cone beam computed tomography scans of an orthodontic sample. Prog Orthod. 2014;15(1):37.

91. Khadija A, Lahlou Y, Chemlali S, Kissa J, Gharibi A, Baite M. Cone beam computed tomography study of intra-sinus calcifications. Glob J Med Res. 2017;17(1):4-13.

92. deShazo RD, Chapin K, Swain RE. Fungal sinusitis. N Engl J Med. 1997;337(4):254-9.

93. Orhan K, Kocyigit D, Turkoglu K, Kartal Y, Arslan A. Illosis of maxillary sinus in immunocompromised patient. Case report. N Y State Dent J. 2012;78(1):46-9.

94. Mossa-Basha M, Ilica AT, Maluf F, Karakoç Ö, Izbudak I, Aygün N. The many faces of fungal disease of the paranasal sinuses: CT and MRI findings. Diagn Interv Radiol. 2013;19(3):195-200.

95. Kishi K, Kawahara K, Moriya I, Komatsu H, Sato M, Aono K. Clinical and radiographic study of multiple miliary osteomas of the skin. Dentomaxillofac Radiol. 1984;13: $105-8$.

96. Shigehara H, Honda Y, Kishi K, Sugimoto T. Radiographic and morphologic studies of multiple miliary osteomas of cadaver skin. Oral Surg Oral Med Oral Pathol Oral Radiol Endod. 1998;86:121-5.

97. Safi Y, Valizadeh S, Vasegh Z, Aghdasi MM, Shamloo N, Azizi Z. Prevalence of osteoma cutis in the maxillofacial region and classification of its radiographic pattern in cone beam CT. Dermatol Online J. 2016;22(1):2.

98. Eisenkraft BL, Som PM. The spectrum of benign and malignant etiologies of cervical node calcification. Am J Roentgenol. 1999;172:1433-7.

99. Garcia HH, Gonzalez AE, Evans CAW, Gilman RH, Cysticercosis Working Group in Peru. Taenia solium cysticercosis. Lancet. 2003;362(9383):547-56.

100. Chakraborty P, Kumari R, Jain RK, Prasad V, Pradhan S, Joshi P. Solitary head and neck cysticercosis: a series of rare cases. Iran J Otorhinolaryngol. 2017;29(95):347-51.

101. Hosur BM, Byakodi S, Puranik RS, Vanaki SS, Puranik RS, Shivakumar SM. Oral cysticercosis: a case report and review of literature. J Maxillofac Oral Surg. 2015;14(3):853-7.

102. Lustigman S, Prichard KR, Gazzinelli A, Grant NW, Boatin AB, McCarthy SJ, Basáñez GM. A research agenda for helminth diseases of humans: the problem of helminthiases. PLoS Negl Trop Dis. 2012;6(4):e1582.

103. Kanlı A, Özkan G. Yumuşak dokuda radyoopak görüntü veren lezyonlar. Turkiye Klinikleri J Dent Sci Special Topics. 2010;1(2):58-65.

104. Avsever H, Orhan K. Calcifications of jaws and related soft tissues. Turkiye Klinikleri J Oral Maxillofac Radiol Special Topics. 2018;4(1):43-52.

105. Bardouni EA, Boufettal M, Zouaidia F, Kharmaz M, Berrada SM, Mahassini N, Yaacoubi EM. Non-traumatic myositis ossificans circumscripta: a diagnosis trap. J Clin Orthop Trauma. 2014;5(4):261-5.

106. Boffano P, Zavattero E, Bosco G, Berrone S. Myoasperapsitis ossificans of the left medial pterygoid muscle: case report and review of the literature of myositis ossificans of masticatory muscles. Craniomaxillofac Trauma Reconstr. 2014;7(1):43-50.

107. Nemoto H, Sumiya N, Ito Y, Kimura N, Akizuki A, Maruyama N. Myositis ossificans traumatica of the masticatory muscles. J Craniofac Surg. 2012;23(5):e514-6.

108. Goldman AB. Myositis ossificans circumscripta: a benign lesion with a malignant differential diagnosis. Am J Roentgenol. 1976;126:32-40.

109. Amendola MA, Glazer GM, Agha FP, Francis IR, Weatherbee L, Martel W. Myositis ossificans circumscripta: computed tomographic diagnosis. Radiology. 1983;149:775-9.

110. Sedghizadeh PP, Nguyen M, Enciso R. Intracranial physiological calcifications evaluated with cone beam CT. Dentomaxillofac Radiol. 2012;41:675-8.

111. Kıroğlu Y, Çallı C, Karabulut N, Öncel C. Intracranial calcifications on CT. Diagn Interv Radiol. 2010;16:263-9.

112. Kwak R, Takeuchi F, Ito S, Kadoya S. Intracranial physiological calcification on computed tomography (part 1): calcification of the pineal region. No To Shinkei. 1988;40:56-74. 
113. Daghighi MH, Rezaei V, Zarrintan S, Pourfathi H. Intracranial physiological calcifications in adults on computed tomography in Tabriz, Iran. Folia Morphol (Warsz). 2007;66:115-9.

114. Mahdian M, Moghaddam EJ, Alzahrani A, Rengasamy K, Tadinada A. Calcification of the stylohyoid ligament in panoramic radiography and cone beam computed tomography among patients referred for dental implant treatment planning. Implant Dent. 2014;23:508-13.

115. Ramadan SU, Gökharman D, Koşar P, Kacar M, Koşar U. The stylohyoid chain: CT imaging. Eur J Radiol. 2010;75:346-51.

116. Lanzer P, Boehm M, Sorribas V, Thiriet M, Janzen J, Zeller T, et al. Medial vascular calcification revisited: review and perspectives. Eur Heart J. 2014;35:1515-25.

117. Tahmasbi-Arashlow M, Barghan S, Kashtwari D, Nair MK. Radiographic manifestations of Mönckeberg arteriosclerosis in the head and neck region. Imaging Sci Dent. 2016;46(1): 53-6.

118. Frazier JJ, Casian R, Benson BW. Mönckeberg medial calcinosis of the infraorbital arteries: a first case report. Oral Surg Oral Med Oral Pathol Oral Radiol. 2018;125(2):e31-5.

119. Romano-Sousa CM, Krejci L, Medeiros FMM, Graciosa-Filho RG, Martins MFF, Guedes $\mathrm{VN}$, et al. Diagnostic agreement between panoramic radiographs and color doppler images of carotid atheroma. J Appl Oral Sci. 2009;17:45-8.

120. Damaskos S, Tsiklakis K, Syriopoulos K, van der Stelt P. Extra-and intra-cranial arterial calcifications in adults depicted as incidental findings on cone beam CT images. Acta Odontol Scand. 2015;73:202-9.

121. Avsever H, Gunduz K, Karakoç O, Akyol M, Orhan K. Incidental findings on cone-beam computed tomographic images: paranasal sinus findings and nasal septum variations. Oral Radiol. 2018;34:40-8.

122. Conrad DA, Jenson HB. Management of acute bacterial rhinosinusitis. Curr Opin Pediatr. 2002;14(1):86-90.

123. Zacharisen M, Casper R. Pediatric sinusitis. Immunol Allergy Clin N Am. 2005;25(2): 313-32.

124. Brüllman DD, Schmidtmann I, Hornstein S, Shulze RK. Correlation of cone beam computed tomography (CBCT) findings in the maxillary sinus with dental diagnoses: a retrospective cross-sectional study. Clin Oral Investig. 2012;16:1023-9.

125. Lana JP, Carneiro PM, Machado Vde C, de Souza PE, Manzi FR, Horta MC. Anatomic variations and lesions of the maxillary sinus detected in cone beam computed tomography for dental implants. Clin Oral Implants Res. 2012;23:1398-403.

126. Bassiouny A, Newlands WJ, Ali H, Zaki Y. Maxillary sinus hypoplasia and superior orbital fissure asymmetry. Laryngoscope. 1982;92:441-8.

127. Hupp JR, Ellis E, Tucker MR, editors. Contemporary oral and maxillofacial surgery. 5 th ed. St. Louis: Mosby Elsevier; 2008. p. 515-20.

128. Weed DT, Cole RR. Maxillary sinus hypoplasia and vertical dystopia of the orbit. Laryngoscope. 1994;104(6 Pt 1):758-62.

129. Thiagarajan B, Narashiman S. Hypoplasia of all paranasal sinuses: a case series and literature review. Otolaryngol Online J. 2012;2(2):1-5.

130. Erdem T, Aktas D, Erdem G, Miman MC, Ozturan O. Maxillary sinus hypoplasia. Rhinology. 2002;40:150-3.

131. Jafari-Povze N, Sheikhi M, Ataie-Khorasgani M, Jafari-Povze S. Aplasia and hypoplasia of the maxillary sinus: a case series. Dent Res J (Isfahan). 2014;11(5):615-7.

132. Mathew R, Omami G, Hand A, Fellows D, Lurie A. Cone beam CT analysis of Haller cells: prevalence and clinical significance. Dentomaxillofac Radiol. 2013;42:20130055.

133. Alkire BC, Bhattacharyya N. An assessment of sinonasal anatomic variants potentially associated with recurrent acute rhinosinusitis. Laryngoscope. 2010;120:631-4.

134. Lloyd GA. CT of the paranasal sinuses: study of a control series in relation to endoscopic sinus surgery. J Laryngol Otol. 1990;104:477-81.

135. Kainz J, Braun H, Genser P. Haller's cells: morphologic evaluation and clinico-surgical relevance. Laryngorhinootologie. 1993;72:599-604.

136. Milczuk H. Nasal and paranasal sinus anomalies in children with chronic sinusitis. Laryngoscope. 1993;103:247-52. 
137. Ahmad M, Khurana N, Jaberi J, Sampair C, Kuba RK. Prevalence of infraorbital ethmoid (Haller's) cells on panoramic radiographs. Oral Surg Oral Med Oral Pathol Oral Radiol Endod. 2006;101(5):658-61.

138. Chmielik LP, Chmielik A. The prevalence of the Onodi cell- most suitable method of CT evaluation in its detection. Int J Pediatr Otorhinolaryngol. 2017;97:202-5.

139. Kainz J, Stammberger H. Danger areas of the posterior rhinobasis. An endoscopic and anatomical-surgical study. Acta Otolaryngol. 1992;112(5):852-61.

140. Badia L, Lund VJ, Wei W, Ho WK. Ethnic variation in sinonasal anatomy on CT-scanning. Rhinology. 2005;443(3):210-4.

141. Koo SK, Kim JD, Moon JS, Jung SH, Lee SH. The incidence of concha bullosa, unusual anatomic variation and its relationship to nasal septal deviation: a retrospective radiologic study. Auris Nasus Larynx. 2017;44(5):561-70.

142. Smith KD, Edwards PC, Saini TS, Norton NS. The prevalence of concha bullosa and nasal septal deviation and their relationship to maxillary sinusitis by volumetric tomography. Int $\mathrm{J}$ Dent. 2010;2010:404982.

143. Goldman JL. The principles and practice of rhinology: a text on the diseases and surgery of the nose and paranasal sinuses. New York: Wiley; 1987. p. 405.

144. Türk B, Akpinar M, Mahmutoğlu AS, Uçak I, Coşkun BU. Anatomic variations in paranasal sinuses of patients with sinonasal polyposis: radiological evaluation. J Craniofac Surg. 2016;27:1336-9.

145. Bolger WE, Butzin CA, Parsons DS. Paranasal sinus bony anatomic variations and mucosal abnormalities: CT analysis for endoscopic sinus surgery. Laryngoscope. 1991;101:56-64.

146. Prasanna LC, Mamatha H. The location of maxillary sinus ostium and its clinical application. Indian J Otolaryngol Head Neck Surg. 2010;62(4):335-7.

147. Earwaker J. Anatomic variants in sinonasal CT. Radiographics. 1993;13:381-415.

148. Jog M, McGarry GW. How frequent are accessory sinus ostia? J Laryngol Otol. 2003;117:270-2.

149. May M, Sobol SM, Korzec K. The location of the maxillary os and its importance to the endoscopic sinus surgeon. Laryngoscope. 1990;100:1037-42.

150. Scheaffer JP. Paranasal sinuses, nasolacrimal passageways and olfactory organ in man. Philadelphia: Blakiston; 1920.

151. Tadinata A, Fung K, Thacker S, Mahdian M, Jadhav A, Schincaglia GP. Radiographic evaluation of the maxillary sinus prior to dental implant therapy: a comparison between twodimensional and three-dimensional radiographic imaging. Imaging Sci Dent. 2015;45:169-74. 